\title{
Online Tutoring in the Calculus
}

Beyond the limit of the limit

\section{Carla van de Sande and Gaea Leinhard}

\section{OpenEdition}

\section{Journals}

Electronic version

URL: http://journals.openedition.org/educationdidactique/695

DOI: 10.4000/educationdidactique.695

ISBN: 978-2-7535-1615-1

ISSN: 2111-4838

\section{Publisher}

Presses universitaires de Rennes

\section{Printed version}

Date of publication: 1 September 2007

Number of pages: $117-155$

ISBN: 978-2-7535-0534-6

ISSN: 1956-3485

\section{Electronic reference}

Carla van de Sande and Gaea Leinhard, "Online Tutoring in the Calculus », Éducation et didactique [Online], 1-2 | septembre 2007, Online since 01 September 2009, connection on 10 December 2020 URL : http://journals.openedition.org/educationdidactique/695; DOI : https://doi.org/10.4000/ educationdidactique.695 


\title{
ONLINE TUTORING IN THE CALCULUS: Beyond the limit of the limit
}

\author{
Carla van de Sande and Gaea Leinhard \\ University of Pittsburgh
}

\begin{abstract}
Résumé :Tutorat en ligne en analyse : vers la limite, et au-delà.
Dans de nombreux pays, des élèves et des étudiants participent à des forums ouverts (c'est-à-dire d'accès libre et gratuit) offrant un tutorat en ligne pour leur travail personnel. Il n'y a eu cependant jusqu'à présent aucune recherche spécifique sur les phénomènes d'apprentissage liés à ce dispositif. Les forums peuvent avoir différentes structures selon les personnes susceptibles d'apporter une réponse (tuteurs) et l'organisation de la modération (publication des questions et des réponses). Dans les sites d'aide spontanée en ligne $(\mathrm{SOH})$, tous les participants peuvent répondre à une question posée; alors que dans les sites d'aide organisée en ligne ( $\mathrm{AOH}$ ), seuls certains participants sélectionnés peuvent le faire. Dans cet article, nous nous basons notre étude sur trois sites d'aide (deux aux Etats-Unis, un en France), à propos d'un même thème mathématique : l'analyse. Le choix de ces sites reflète les différentes structures possibles. Nous avons recueilli et analysé 100 échanges de tutorat de chaque site, à propos du délicat concept de limite. Nos objectifs étaient de rechercher des caractéristiques de participation, de qualité mathématique et pédagogique, et de comprendre dans quels sens les participants à ces forums peuvent être considérés comme participants à des communautés. Nous avons développé dans cet objectif des outils de mesure de la complexité et de la qualité des échanges, et relevé plusieurs types de caractéristiques permettant de considérer des groupes de participants comme des communautés en ligne. Nous avons remarqué que les sites de type AOH favorisent les échanges brefs à l'intérieur d'un binôme élève-tuteur (complexité faible), alors que les sites SOH (particulièrement ceux qui publient les questions et les réponses dans des délais brefs) encouragent des échanges longs impliquant de multiples participants (complexité élevée). La différence entre le type des sites est plus importante que des différences de nationalité. Il semble également que la qualité et la complexité soient positivement corrélées. Les échanges impliquant peu de participants, avec peu de contributions (faible complexité) montrent souvent peu d'élaboration mathématique et pédagogique (qualité faible). Sur les sites $\mathrm{SOH}$, les membres paraissent développer un plus fort sentiment communautaire : ils réfèrent les uns aux autres par leur nom, collaborent mathématiquement, critiquent et corrigent les fautes, les erreurs les uns des autres. L’un des résultats particulièrement intéressants que nous avons pu observer est que sur les sites $\mathrm{SOH}$, les tuteurs adoptent également une position d'apprenant.

Cette recherche fait partie d'un effort en cours pour comprendre l'impact que le tutorat ouvert en ligne a sur les élèves et les tuteurs et explorer son potentiel pour l'instruction et l'apprentissage.
\end{abstract}

\section{Carla van de Sande E Gaea Leinhardt}

When a new technology appears in a culture the first stage of its presence is often felt as a simple replication of activity, but by the use of new means. Consider, for example, the movement of water supplies from hauling buckets from a nearby river to having a town well to having running piped water in every home; or the support of writing from scribe to typewriter to computer. In each case the central activity remained the same for a while and then was transformed by the unique affordances and demands of the new technology. This transformation folds back on itself so that the culture that supports the activity reconsiders its fundamental purpose. We are at such a place with respect to student learning and teaching in mathematics. The current timing, sequencing, and resources available to the mathematics student seem to be more or less the following: the student learns in a classroom with a teacher; engages in individual or group assignments that appear in the text book or are given out; and checks the work by consulting with other students, other texts, or occasionally additional adults. If a student struggles consistently with the content and procedures of mathematics, perhaps there are arrangements for formal tutoring support either for additional payment outside of school or in a special support session inside the school.

The presence of free, open, online tutoring resources has altered this scenario. Students can simply log on to a website and immediately pose a concern, problem, or issue of confusion to a group of highly knowledgeable and willing responders. Students can ask their questions when they wish and 


\section{Carla van de Sande E Gaea Leinhardt}

from the convenience of their home or school. The contact is asynchronous in many senses - the student may ask the question at a time different from when the answerer is available, at a time different from when the ideas are discussed in school, and out of sequence from assigned work. The tutorial response is highly specific and goes directly to the question asked but is agnostic with respect to the particular slant that the teacher or textbook might have taken on the matter. Thus, the online conversation is both stripped down - it does not contain many entrance negotiation moves, it does not make internal references to other parts of the lessons or texts, but it is also more detailed and elaborate. Because the tutors have no idea what exactly has and has not been discussed or what the history of understanding is on the part of the particular enquirer, more specificity and detail must also be included in the question. In a Gricean (1989) sense the conversational implicatures require simultaneously more and less information.

In order to start to understand this new technology and its impact, we have begun to gather a substantial corpus of online tutorial exchanges in calculus help forums. We have focused our efforts on three topics within the calculus: the limit, the chain rule, and related rates (conceptual, procedural, and integrated). We are inspecting this corpus through a number of lenses (cognitive, situative, perspectival) and posing a number of questions, a few of which are the following: Does the form of the arrangement of the help site influence the kind of exchanges that take place? Do the exchanges show evidence of explanatory completion? How do these online exchanges compare qualitatively to face-toface tutoring sessions? In what sense are these online help sites communities? How do community norms for exchanges evolve over time? What can we learn about the way in which instruction might be better designed from examining the nature and depth of the questions posed? In this paper we examine the ideas of participation, quality instruction, and an emerging sense of community as students and tutors engage in a series of questions and responses. At a deeper level we want to examine how this new form of support for student learning may alter the very nature of instruction or what we take to be instruction.

\section{Community}

The notion of a community of learners is a central construct in analyzing and understanding instructional practices (Bruner, 1986; Brown, 1997). Classrooms are considered communities of practice and the participation, positioning, and growth of individuals within this community contribute to an understanding of the instruction and learning that is taking place. As the Internet is becoming a ubiquitous means of communication and instruction, the question of defining community in this new context arises. Some have posited the idea of a virtual community, while others have suggested that the idea of a virtual community is an oxymoron. While not wanting to take on the fundamental issue of what is and is not a community, we do feel that there are features in an online environment that make it community-like. That is, the activity and participation of members in online help sites reflects the common themes found across theories of community as well as the feature shared norms and goals (Carter, 1998; Wertheimer, 1998). Appealing to the notion of what constitutes an online learning community, we consider the presence of the following attributes as indications of an open online tutoring community (Grossman, Wineburg, \& Woolworth, 2001; Lave, 1991; Palloff \& Pratt, 1999; Pratt, 1996; Werry \& Mowbray, 2001):

1. Participants share some common explicit and implicit goals.

2. Participants have an accessible physical or virtual location in which they meet.

3. Participants identify themselves as members of the community.

4. Participants assume responsibility for participation.

5. The defining features of the community can be renegotiated and altered by the members.

6. Ideas can be questioned, elaborated, challenged, and revised safely.

The participants in open online help forums are positioned as students (those who request help) and tutors (those who provide assistance) ${ }^{1}$. In general, the tutors are more regular participants; students use the forum as the need dictates but tutors consistently participate (often on a daily basis). Therefore, the tutors are the core group of participants that provide 
the sense of community. In this paper, we identify several ways in which open online help forums manifest the features of community listed above, with special attention paid to the attributes concerning responsibility for participation, the establishment of principles, and the exchange of ideas.

\section{Tutoring}

Tutoring has often been considered a face-to-face, single tutor-student pair activity that has the goal of instructing the student on a pre-determined set of concepts or procedures. This form of instruction has proven effective for academic performance and attitudes toward subject matter. In what has become a classic piece of literature in the field, Bloom (1984) documented that students learning from tutors in this way perform two standard deviations above students learning in a classroom situation.

In order to account for the tutoring advantage, the characteristics of participants and exchanges have been examined. Somewhat surprisingly, the tutoring advantage does not appear to be attributable to the tutors level of expertise (Graesser \& Person, 1994) or the familiarity of the participating parties (McArthur, Stasz, \& Zmuidzinas, 1990; Siler \& VanLehn, 2005). Instead, the advantage of tutoring may be attributed to the opportunity it presents for students to ask questions (Graesser \& Person, 1994), the intensity of the interaction (McArthur, Stasz, \& Zmuidzinas, 1990), and the cues from tutors that maximize the motivation to learn (Lepper, Aspinwall, \& Mumme, 1990). Of key importance is the finding that tutoring sessions do not generally embody a large set of the elements of idealized instruction. Graesser, Person, $\&$ Magliano (1995) found evidence for only three elements (collaborative problem solving, question answering, and explanatory reasoning in the context of specific examples) in tutoring sessions.

One can conclude that tutoring is a highly interactive process in which support is provided in ways that are markedly different than other instructional settings. However, in addition to treating tutoring as one-on-one, face-to-face instruction covering a pre-determined set of material, the majority of the research has also been conducted in the laboratory. A more naturalistic approach to tutoring is worth pursuing. Students often seek help from others on particular problems they encounter while completing homework assignments or preparing for examinations. This form of tutoring or student-initiated helpseeking has not been as systematically studied.

Open online help communities are a relatively unexplored instantiation of tutoring, despite the fact that these communities are developing and flourishing across the world. Investigating these communities locates tutoring in a natural setting and is important because these sites may be the only recourse that some students have for gaining instructional support outside of the classroom. In this paper we address the issues of complexity and quality in the context of online help forums. Within a student-initiated help-seeking discussion, the number of participants and the duration of the discussion contribute to its complexity and the depth of explanation and pedagogical sophistication mark its quality.

\section{The calculus}

We have chosen to use online tutoring help sites on the calculus as a location of study. The calculus functions universally as a gate-keeper for the physical, biological, and many of the social sciences. It is viewed as extremely challenging by many students and introductory courses often have high attrition rates. Teachers tend to view success or failure in the calculus as an indication of underlying capability and, in the United States, success in the course is often a pre-requisite for admission to programs that in fact use very little calculus in the content of their own domain. One of the first challenges facing a student in an introductory calculus course is coming to grips with the concept of the limit.

The concept of limit is foundational to calculus and is a recurring theme in any introductory course. However, the concept contains nuances that took mathematicians over a century to resolve (Dunham, 2005) and pose numerous problems for introductory calculus students (Szydlik, 2000). Students often experience confusion regarding the relationship between the value of a function at a point (or nearby points) and the limit, the meaning of indeterminate forms, and the notion of boundedness. In addition, there is a large set of procedures (such as factoring, multiplying by the conjugate, and rearranging terms) associated with the computation of limits. Deciding which technique to apply in a given situation can be a daunting task, and resolving 
these quandaries is at the heart of gaining an understanding of calculus that will support future learning (Tall, 1992).

As a part of our on-going effort to understand the ways in which the Internet has altered instruction and learning (writ large) and has become a support for topics such as the calculus more specifically, we address the following questions in this paper: How might we set up an appropriate methodology for studying these environments? What is the effect on participatory engagement of different kinds of online forums? What is the range of quality that we see in these environments? What is the nature of the "community" of participants?

\section{METHODS}

\section{Vocabulary}

There is a vocabulary associated with interaction in online environments that we have appropriated for our discussion of online tutoring. A post(ing) is a contribution that is published on the site, either to initiate a discussion or in response to another's contribution. As in verbal discussions, participants generally take turns contributing to the conversation. The set of contributions pertaining to a single request for help constitute an exchange or discussion, sometimes referred to as a topic

\section{Sites}

There are a large number of free, open, online tutoring websites. These sites exist in many countries; and among those countries that share a language (English or French, for example) students and tutors can and seem to traverse geo-political boundaries. Although similar in many ways, online help sites can be structured differently with respect to who may respond (tutor) and how monitoring is accomplished (when questions and answers get posted). We selected three calculus help sites to reflect these differences. FreeMathHelp.com (U.S.) allows any registered participant to respond immediately and has select participants who subsequently moderate the discussions. Cyberpapy.com $(\text { French })^{2}$ also allows any registered participant to respond but has moderators screen ${ }^{3}$ the replies before they are made public. MathNerds.com (U.S.) only permits select tutors (based on mathematical qualifications and tutoring performance) to respond and assigns each query to a particular tutor. Based on the rules for whom may participate as tutors and how responses occur, we refer to FreeMathHelp.com and Cyberpapy.com as Spontaneous Online Help ( $\mathrm{SOH}$ ) and MathNerds. com as Assigned Online Help (AOH). One effect of the monitoring feature is on the speed of responses. If there are no intermediate monitoring actions, then the response can be as quick as a real time face-to-face question and answer; on the other hand, if a monitoring action requires both an assessment of the question and an assessment of the availability of a specific tutor to deal with the question, then there may be a considerable delay - up to several days - between the time the question is asked and the answer is presented. Thus, there is a trade-off between the certainty of a response and its timing; in unmonitored sites it is possible that no one chooses to pick up on a question.

FreeMathHelp.com. FreeMathHelp.com is an advertisement-supported mathematics help portal established in 2002 by Ted Wilcox, an enterprising high school junior. In addition to the discussion forum, the site includes lessons, games, a graphing utility, and worksheet pages. There are 9 homework help forums, organized by subject area (such as algebra, differential equations, calculus). Forum members can contribute or respond to these postings and have access to user profiles that include volunteered information on occupation, residence, contact information, as well as amount of discussion board activity. Each member is characterized by total number of contributions to distinct postings: new (0$49)$, junior (50-249), full (250-999), senior (10002499), elite (more than 2500). There are several elite members with more than 2500 contributions, four of whom have contributed to more than 4000 postings each. Each forum has assigned moderators who have the right to lock topics and move or delete postings; but who do not affect the pace of responding.

The prescribed etiquette for participation is located in a "sticky" that is the lead posting within each help forum. This covers administrative issues (e.g. posting to an appropriate category) and politeness (e.g. patience while waiting for response). In addition, there are 3 rules that specifically address the content and framing of posts: include problem context ("Post the complete text of the exercise"), 
show initial work ("Show all of your work [including intermediate steps that may contain errors]"), and attend to clarity ("Preview to edit your posts [to minimize errors]").

The computer window for constructing posts contains traditional icons for highlighting text (e.g. italics, boldface, underlining, and font size and color), inserting material (e.g. external links and images), and organizing text (e.g. forming lists). A large selection of graphic "emoticons" (faces) is available for expressing emotions and attitudes (such as gladness or perplexity). In addition, there are format capabilities more specific to mathematical discussions since it is tedious and often impossible to create mathematical symbols and expressions using keyboard characters. Using LaTeX, a document preparation system designed to typeset mathematical text, participants can use command strings and code to produce mathematical symbols (such as $\mathrm{II}$ ) and vertical expressions (such as $\lim _{x \rightarrow-1} \frac{x^{2}-1}{x+1}$ ). In order to encourage the use of this software, FreeMathHelp.com includes a tutorial for LaTeX, as well as a link to a free equation editor that generates the LaTeX code, which, although powerful, can be difficult for the novice ${ }^{4}$.

Cyberpapy.com. Cyberpapy.com was founded in 1997 by the Boulanger Foundation to connect youth and seniors, with the premise that many seniors ${ }^{5}$ have the time, expertise, and willingness to help young people with academics. The site includes discussion forums for 10 subject areas (including mathematics). Within each subject areas, postings are indexed by title, number of responses, initiator, date, and school level.

The prescribed Cyberpapy.com participation etiquette is similar to that of FreeMathHelp.com with respect to administrative issues and politeness (e.g. students are reminded to be patient). However, unlike FreeMathHelp.com, students are not specifically instructed to show work on the problem in question. Tutors are encouraged to provide support in understanding versus providing complete worked solutions.

The computer window for constructing posts contains areas for identifying the author, a short header, the message, and the author's e-mail address. There is also an equation editor to enable the inclusion of mathematical formulas and symbols. Upon request, contributors receive notification via e-mail when others contribute to the exchange. All contributions pass through a system of moderation before being published on the site, a process that may take several hours.

MathNerds.com. MathNerds.com is a nonprofit corporation founded in 1999 by Valerio De Angelis and W. Ted Mahavier. The primary purpose of MathNerds.com is to provide "free, discoverybased, mathematical guidance via an international, volunteer network of mathematicians." In particular, MathNerds.com promotes help via guidance, references, and hints versus worked solutions. The site is available in both English and Spanish and includes links to other "useful" websites (intended for reference and supplementary materials).

MathNerds.com has 325 mathematics tutors, the majority of whom are Ph.D.'s in mathematics. Tutors are selected through an application process that is based on the pedagogical approach and clarity demonstrated in response to 5-10 practice questions. Accepted tutors then specify the number of questions within various categories that they will address each week. The categories are arranged by grade level (e.g. U.S. K-5 Elementary) or by subject area (e.g. Calculus I).

MathNerds.com has a systematic way of assigning tutors to incoming queries. Upon visiting the site, a student first chooses the category that matches the content of the question. If there is a tutor who has selected that subject area and has not met her/his weekly cap, then the student is presented with the terms and conditions of participation (e.g. expectations and obligations for response time and legal disclaimers). The student then posts the question in a screen that includes areas for the subject (5 -10 words), the statement of the question, and any work already done. Instructions for accurately typing mathematical information (e.g. notation) are provided directly above the area for posting the question via a link to an online calculus course (Karl's Calculus Tutor). Encouragement is given to show all attempts at solving the problem(s) (including incorrect ones) along with general help-seeking advice (e.g. searching the published web questions and answers first for solutions to similar problems). After the student submits the question, two automated e-mails are sent: a confirmation of receipt to the student and the question (with a link to the online response form) 


\section{Carla van de Sande E Gaea Leinhardt}

to the assigned tutor. The tutor can reject the question and move it to a general queue (where another tutor may respond) or elect to respond within 2-7 days. If the tutor does not respond within 2 days (and has not indicated that a response is forthcoming), the question is automatically routed to the general queue, where it remains for 2 weeks. If the tutor does respond within a week, the solution is archived and forwarded to the student along with a link for future assistance on the question. The student can then engage in further dialogue (exclusively) with the same tutor that initially responded.

The sites we chose to investigate represent various configurations of online tutoring site structure and differ with respect to nationality, the requirements to participate, and the system of moderation. FreeMathHelp.com (U.S.) allows any registered member to participate as a tutor and moderates exchanges after they have been published. Cyberpapy.com (French) also allows any member to participate as a tutor but moderates exchanges before they have been published. MathNerds.com (U.S.) only permits select tutors to participate and moderation is performed after exchanges have been published.

These sites were also chosen because they provide exemplary asynchronous online mathematical tutoring. The example (Figure 1) from Cyberpapy. com gives the flavor of the kinds of exchanges:

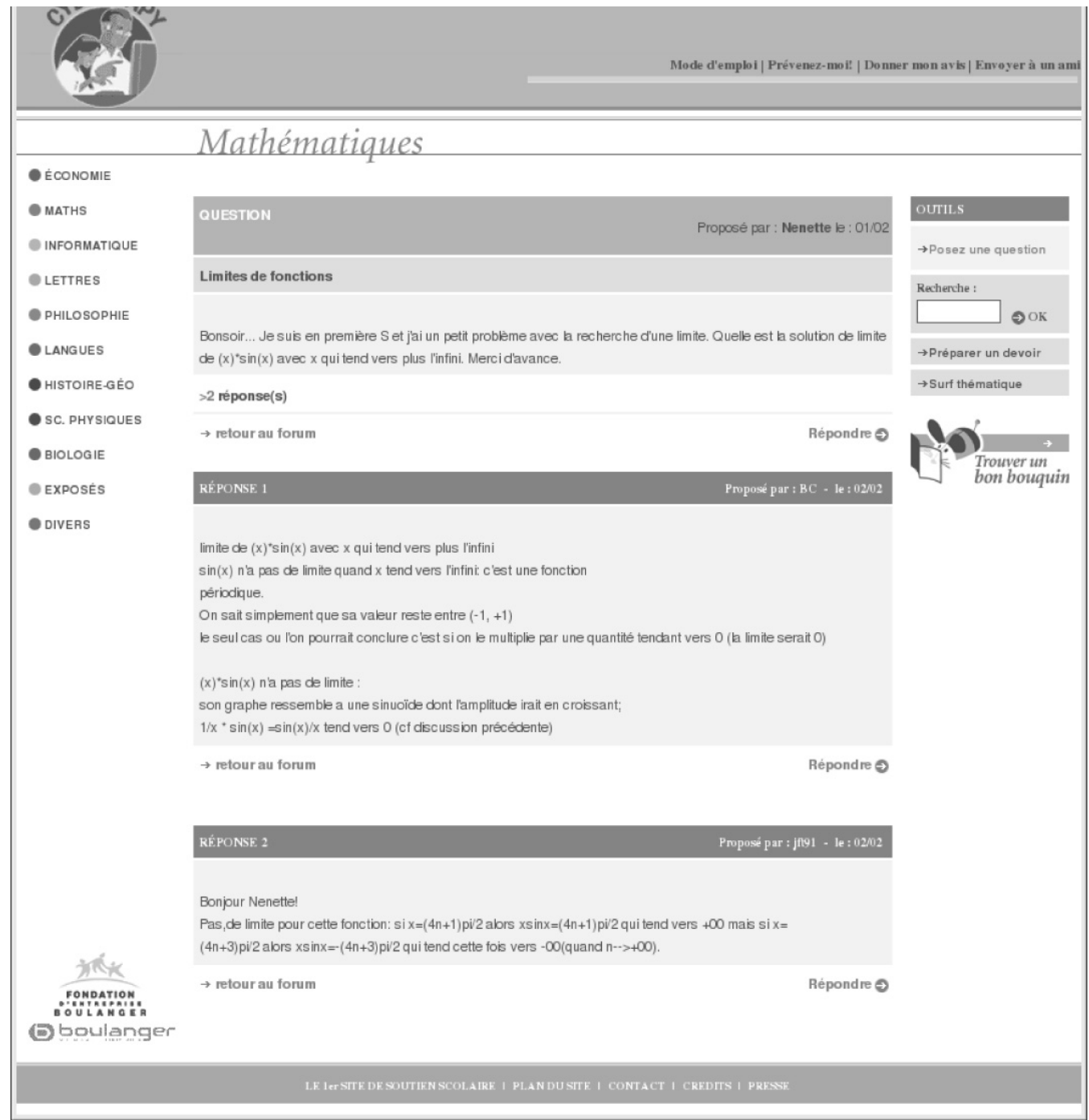

FIGURE 1 Online tutoring exchange in the calculus from Cyberpapy.com 
In this exchange, two tutors provide correct and complementary responses to a student's query regarding the mathematical concept of limit. One tutor (BC) provides an explanation that builds on the general properties of the function $\sin (x)$, namely its periodicity and boundedness, and includes the conditions necessary for an alternative conclusion. BC also promotes the idea of coherence across multiple representations by describing the graph of the function as providing supporting evidence for the argument. The other tutor (Jft91) contributes a complementary explanation that is based on the consideration of specific sets of values, namely $(4 n+1) \mathrm{pi} / 2$ and $(4 n+3) \mathrm{pi} / 2$, that demonstrate conditions that support the conclusion. Together the two tutors give both an object and process sense of the functions involved.

\section{Sample}

After identifying the online tutoring sites, the next step in our investigation was the choice of a methodological approach. We deliberately chose a purely observational and non-intrusive approach for the investigation of these online help sites ${ }^{6}$. We have observed several online help sites for extended periods of time and collected a corpus of hundreds of calculus tutoring exchanges. We have catalogued those into sets by topic and by time of posting. For each investigation we draw a new sample (without replacement) in order to be careful not to over generalize our findings from one analysis to another.

A defining characteristic of free, open, online tutoring sites is the public availability of the discussions. However, some tutoring websites conserve resources by deleting exchanges following a set amount of time (usually, several months). The three sites we chose for this research have extensive archives (dating back several years) and a search mechanism for locating exchanges by a keyword or phrase. We selected 100 postings on the concept of limit from each of the three sites described.

There are numerous exercises that may accompany instruction on the limit concept. Traditional exercises involve estimating limits numerically or graphically, computing limits algebraically, and proving limits using the formal definition. Instruction may also address limits of sequences (versus functions). In recognition of the differing content and sequencing of mathematics instruction in France and U.S., we chose to select online tutoring exchanges that specifically pertained to the algebraic computation of the limit of a function ${ }^{7}$. The exchanges were selected from sequential postings in each site dating back from the same date. We included only those queries that received response, since unanswered queries are not publicly available for MathNerds.com, the $\mathrm{AOH}$ site. However, this decision should not strongly affect the data set since the three sites all report very high response percentages: Cyberpapy. com (90\%), MathNerds.com (98\%), FreeMathHelp.com ${ }^{8}$ (94\%).

\section{Population}

The availability of participants' profiles (tutors, in particular) is one of the features that free, open, online tutoring forums may include. Of the three sites, we chose, only FreeMathHelp.com has this feature. The participating tutors in this calculus forum are self-reportedly students, educators, professionals, and retired mathematics professors. Although individual profiles are not available for Cyberpapy. com and MathNerds.com, both of these sites elicit participation from tutors with Ph.D.'s in mathematics. MathNerds. com, in particular, is almost exclusively devoted to tutoring by mathematicians with Ph.D.'s. Students are not generally accepted as tutors and only a few high-school math teachers and undergraduate and graduate math majors are selected to participate. ${ }^{9}$

Most participants of open, online tutoring forums select names or "handles" (such as Alice or Galactus) that do not disclose personal information (location, knowledge level, etc.), and we refer to such participants using these self-designated handles. However, in order to respect privacy for data from this public forum, we refer to any participants whose handle appeared to reveal identifying information (such as surname) by pseudonyms that we constructed. We notice several individuals appear to frequent a variety of open, online help sites and preserve the same handle across the different sites.

The population of participants in each site is quite varied. Although some tutors and students post more frequently, each of the three sites has numerous tutor and student participants. Table 1 contains the number of unique tutors and students in our sample of 100 for each site. 
TABLE 1

Percentage of Unique Tutors and Students in each Sample

\begin{tabular}{|l|c|c|c|}
\hline & FreeMathHelp & Cyberpapy & MathNerds \\
\hline Tutors & 24 & 73 & $25-66$ \\
\hline Students & 67 & 84 & 81 \\
\hline
\end{tabular}

FreeMathHelp.com has the smallest number of participants, indicating frequent repeated participation during the time period from which we were sampling (or possibly a higher density of exchanges since we 'stopped' when we had 100 exchanges). Cyberpapy.com is remarkable for the diversity of both student and tutor populations, although these numbers may be somewhat inflated due to the site registration policy. Because each participant enters a handle at each posting (instead of registering and accessing this information via "logging in"), there is a possibility that the same individual will be represented by different handles. MathNerds.com encourages but does not require tutors to sign their responses (by name or pseudonym), and, in our sample, only 24 tutors chose to do so. We can conclude that the number of different tutors in our sample ranges from 25 (if all of the unsigned responses were authored by a single tutor) to 66 (if each unsigned response was authored by a different tutor). The number of student participants for MathNerds.com was comparable to that of Cyberpapy.com.

\section{Coding}

In order to detect the impact of the different site structures on participation, we constructed codes that tracked the number of participants, the total number of contributions in the exchange and the sequence of participation. For example, a code of 1231 would characterize a discussion between 3 participants with 4 total contributions: a student [(1)] posted a problem and then two different tutors [(2) and (3), respectively] responded, followed by a final contribution by the student. As a gross measure of the complexity of each discussion, each discussion was assigned a complexity index defined as the sum total of the elements in the code. Thus, a discussion with participation code 1231 would be assigned an index of 7 . Coding in this way blurs what may eventually turn out to be important distinctions in the exact pattern of exchange, but it helps collapse what becomes an increasingly differ- entiated sequence of possible configurations. For example, is a sequence of 1234141311 dramatically different from 1231414311, or is it simply a matter of timing? Coding exchanges in a way that retains sequencing, number of participants, and number of turns will allow us to address different questions at a future time.

To assess the quality of the exchange, we assigned a rating from 1 to 5 for the totality of each exchange. A 1 was assigned to those postings that were both brief and contained little or no rich explanatory or mathematical material; a 5 was assigned to those exchanges that had a truly mathematical feel to them invoking principles, mathematical reasoning, and to some extent excitement. An important feature of these exemplary exchanges was that the student remained positioned as a focal participant in the exchange. Table 2 contains a description of some of the features that differentiated exchanges. This analysis permitted us to describe both sites and specific topics as containing elaborated complete mathematical discussions or sparse mathematical fragments. Inter-rater agreement was $90 \%$ and all differences were resolved following discussion.

TABLE 2

Select Features Distinguishing Exchange Quality

\begin{tabular}{|l|l|}
\hline Rating & Features \\
\hline 1 & $\begin{array}{l}\text { Brief exchange with little or no rich explanatory or } \\
\text { mathematical material. }\end{array}$ \\
\hline 2 & $\begin{array}{l}\text { Generally brief exchange with sparse explanations or few } \\
\text { connections to other mathematical material. }\end{array}$ \\
\hline 3 & $\begin{array}{l}\text { Exchange in which actions are prescribed but may not } \\
\text { include reasons for application. Conditions of use are } \\
\text { largely absent when principles are invoked. }\end{array}$ \\
\hline 4 & $\begin{array}{l}\text { Generally longer exchange invoking principles in which } \\
\text { the mathematical reasoning is somewhat difficult to } \\
\text { follow. Student may be peripheral participant. }\end{array}$ \\
\hline 5 & $\begin{array}{l}\text { Extended exchange in which principles of the calculus } \\
\text { are invoked and perspicuous mathematical reasoning is } \\
\text { evident. Student positioned as focal participant. }\end{array}$ \\
\hline
\end{tabular}

To discern whether participants in open online help sites act as members of a community, we surveyed the exchanges for attributes corresponding to the common themes and features found across theories of community, as discussed above. For example, referring to others by name is an indication of participants identifying themselves as members of the community. For some of the 
attributes, we identified a variety of indicators. For instance, taking turns within an exchange, adopting roles, and sharing the load are all indicators of an assumption of responsibility for participation.

\section{RESULTS}

\section{Participation patterns}

Table 3 contains the percentage of discussions in each homework help site according to the complexity index (defined as the summed participant code entries).
TABLE 3

Percentage of Exchanges in Complexity Range

\begin{tabular}{|c|c|c|c|}
\hline $\begin{array}{c}\text { Complexity } \\
\text { Index }\end{array}$ & $\begin{array}{c}\text { FreeMathHelp } \\
(\mathrm{SOH})\end{array}$ & $\begin{array}{c}\text { Cyberpapy } \\
(\mathrm{SOH})\end{array}$ & $\begin{array}{c}\text { MathNerds } \\
(\mathrm{AOH})\end{array}$ \\
\hline 3 & 18 & 32 & 54 \\
\hline $4-6$ & 27 & 32 & 35 \\
\hline $7-10$ & 30 & 21 & 11 \\
\hline $11-15$ & 17 & 8 & 0 \\
\hline $16+$ & 8 & 7 & 0 \\
\hline
\end{tabular}

Low indices reflect discussions that are brief (contain few turns) and involve a small number of participants. For example, the following exchange (Figure 2) from MathNerds.com, in which a student posts a problem and receives a single reply, has the lowest complexity possible (index $=3$ ):

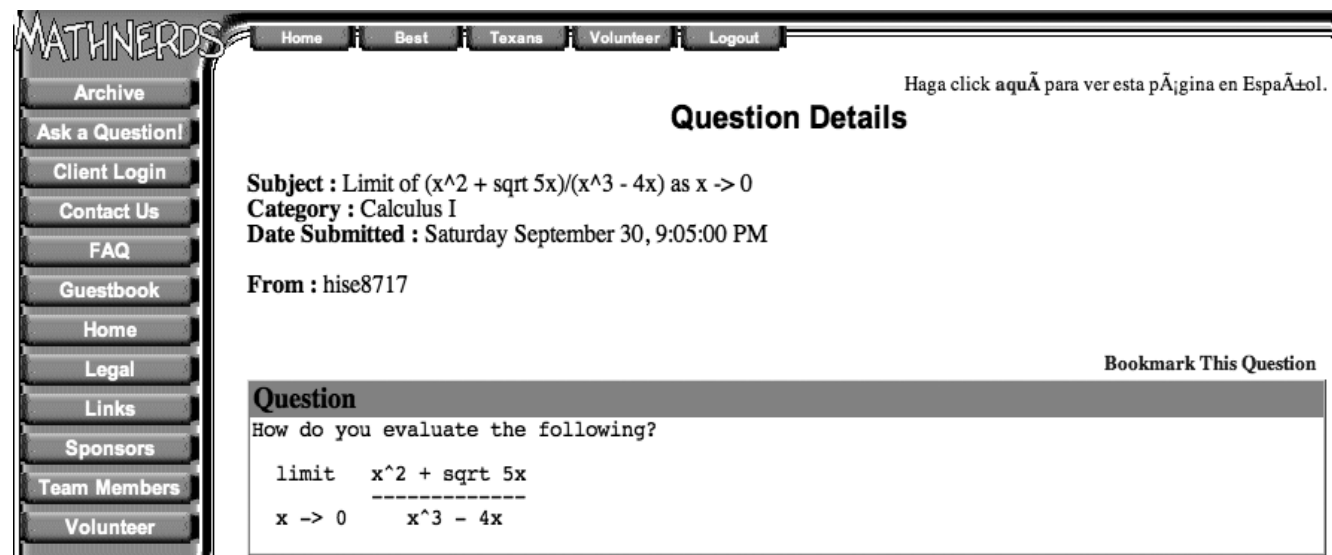

\section{Work Done}

I stared out by dividing the numerator and denominator by $x^{\wedge} 3$, but I don't know where to go from there.

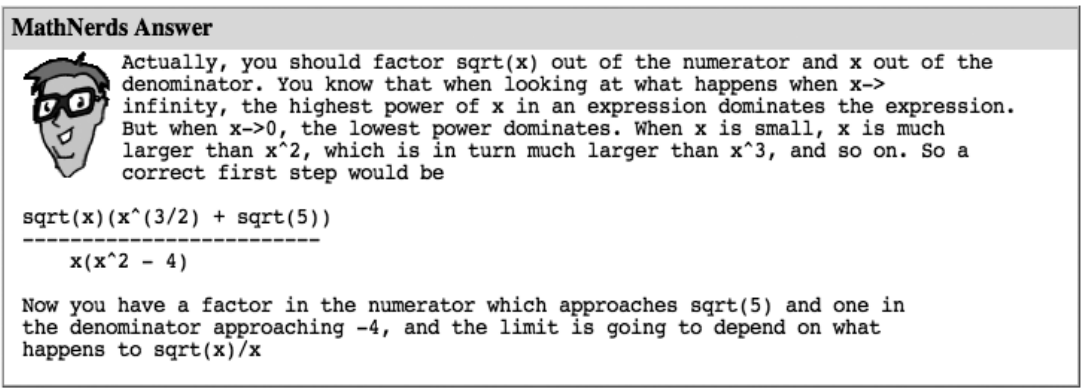

FIGURE 2 Online tutoring exchange of low complexity from MathNerds.com. 
In contrast, higher indices are indicative of extended discussions (many contributions) between several participants. The following exchange
(Figure 3) from Cyberpapy.com contains 7 contributions by six participants (index $=22$ ).

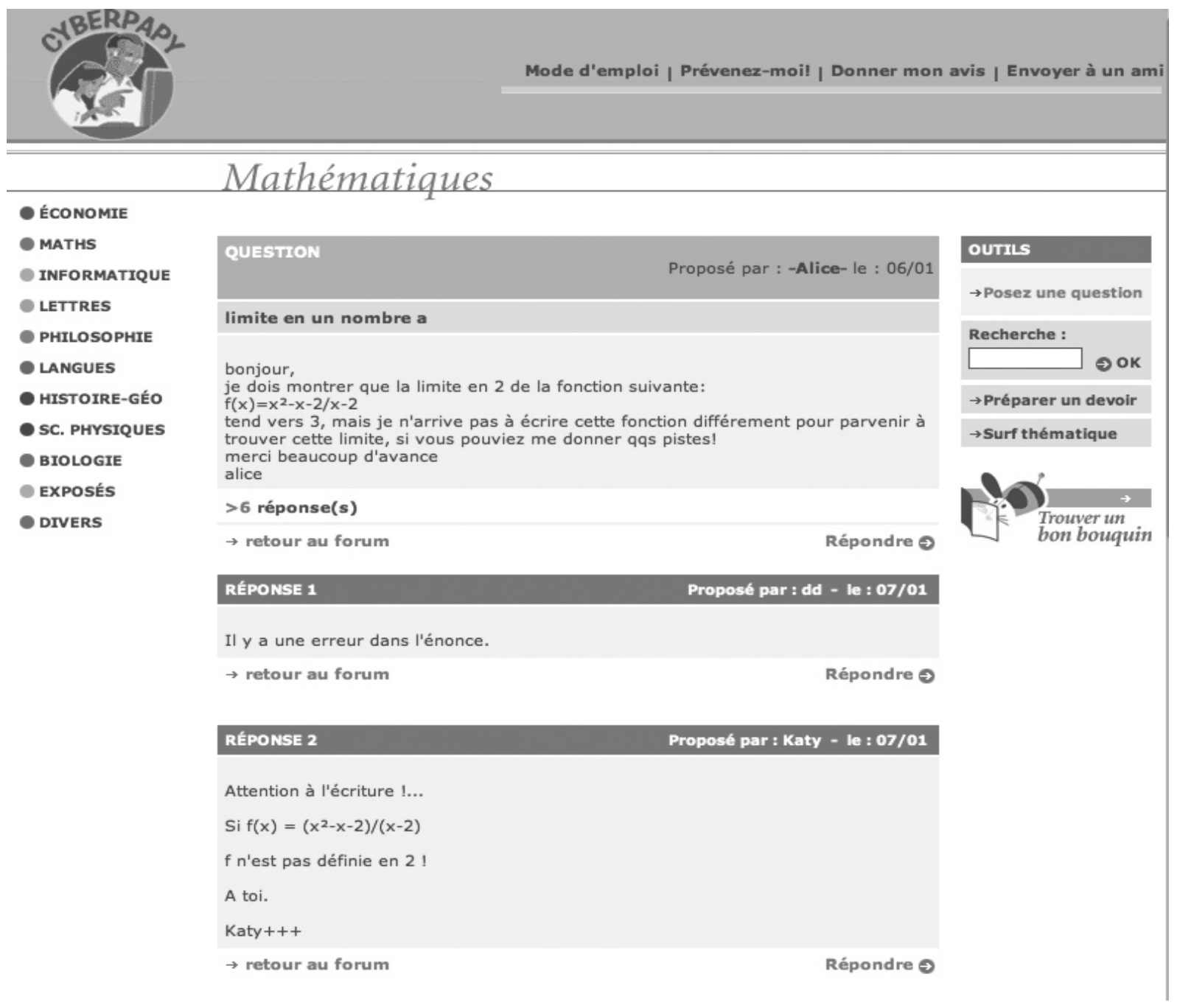




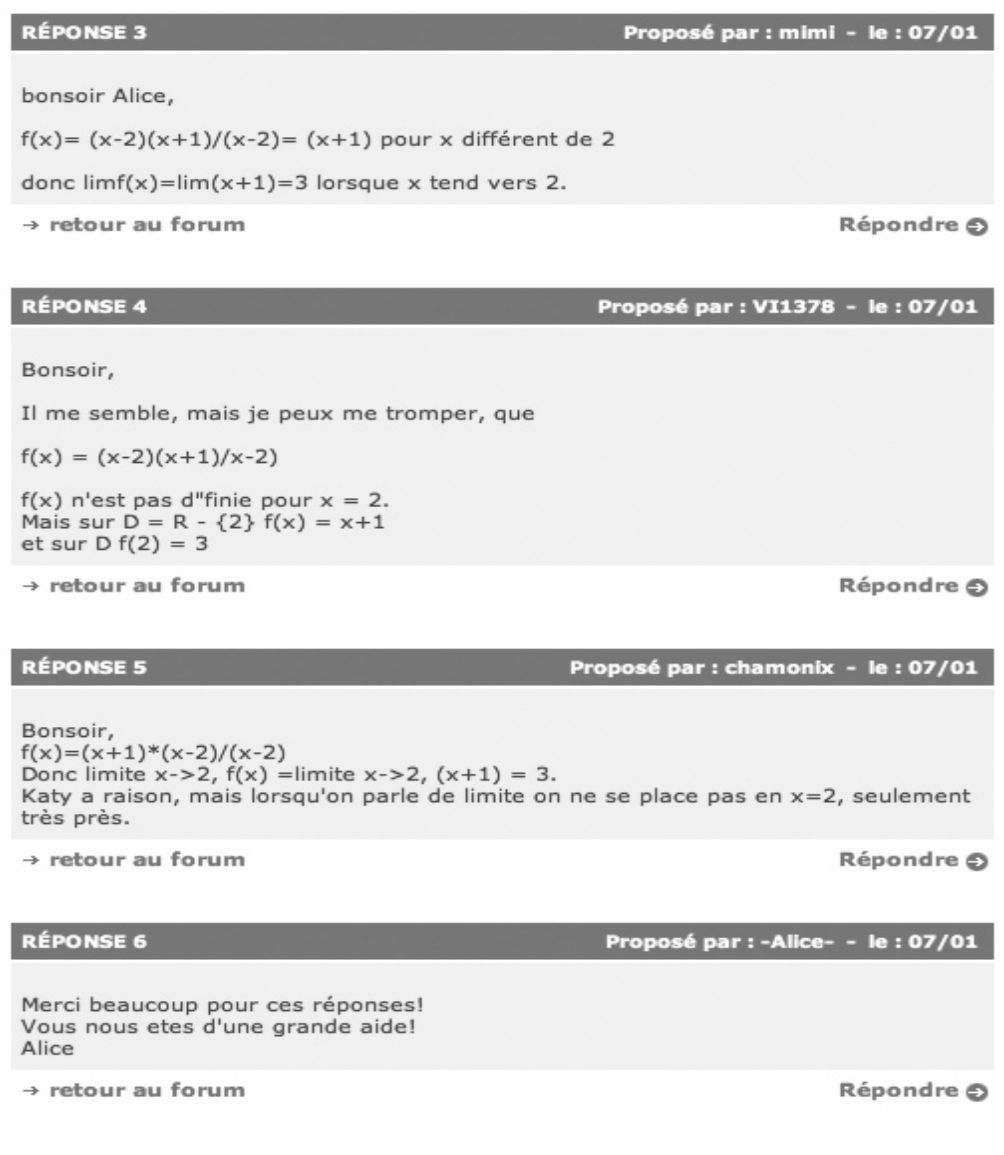

LE 1er STIE DE SOUTIEN SCOLATRE | PLAN DU STIE | CONTACT | CREDITS | PRESSE

FIGURE 3 Online tutoring exchange of high complexity from Cyberpapy.com.

As Table 3 shows, the most notable difference in patterns of participation occurs in row 1 and rows 4 and 5. The overall pattern suggests that the $\mathrm{AOH}$ site has more brief exchanges (54) and fewer extended (index > 11) complex exchanges (0) when compared to the SOH sites (18 and 25 respectively). All of the $\mathrm{AOH}$ discussions are relatively brief and among few participants. Indeed, none of the $\mathrm{AOH}$ discussions has a complexity index greater than 10 and there are relatively few with an index greater than 6 . The most prevalent pattern of participation for this structure consists of a tutor replying to a student query (as in the example), perhaps followed by an expression of thanks.

The predominance of brief exchanges in the AOH structure may be attributable to the "assigned" characteristic that encourages discussions between a single student-tutor pair as well as to response latency. Upon receipt of a query, MathNerds.com assigns a tutor (based on interest and quotas) and informs her/him via e-mail. The tutor then has 27 days ${ }^{10}$ to respond to the query. Due to this delay between requesting and receiving help, students may be disinclined to ask follow-up questions, particularly if the need for help is immediate (e.g. for a homework assignment).

The $\mathrm{SOH}$ sites, in contrast, contained quite a few extended discussions between multiple participants (as in the example from Cyberpapy.com), although FreeMathHelp.com supported even more discussions of this type. The discussion (Figure 4) from FreeMathHelp.com (index $=13$ ) is between a student and 3 tutors: 
Online Tutoring in the Calculus: Beyond the limit of the limit

Carla van de Sande E Gaea Leinhardt

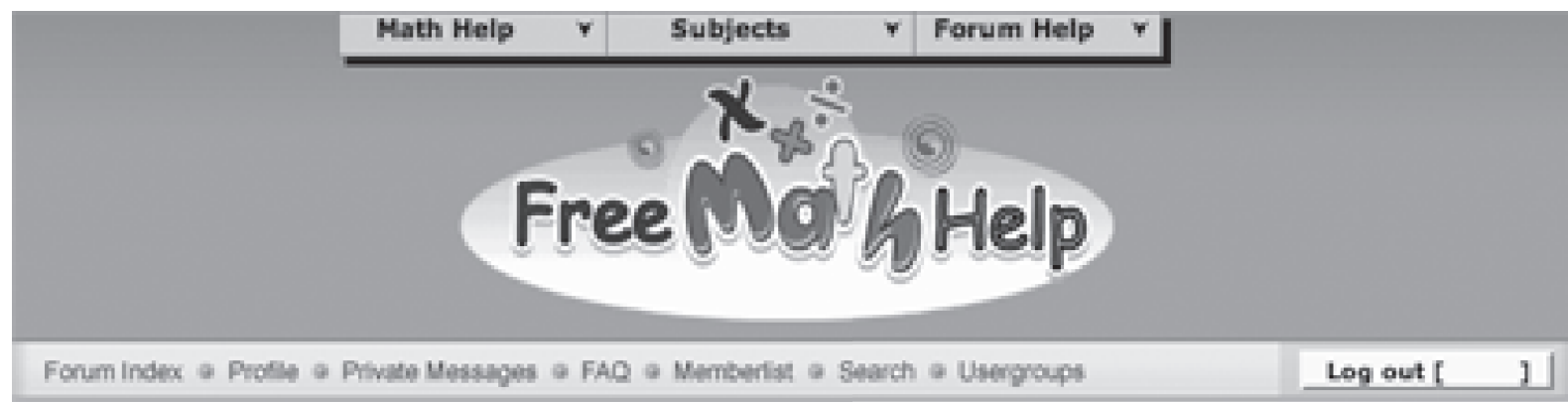

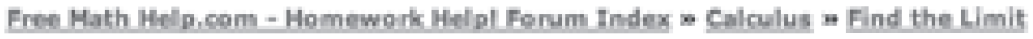

new tope post repi
Yinw poste dnch last rht vitw reur pott Yiow previeus topic a View nent fopic Solve your tough algebra problems with Alqebra Solved

Find the Limit

QFosted! Fin Mar 63, $9: 22$ pm what is the ims to this questan? Im not sure how you find the limit for this

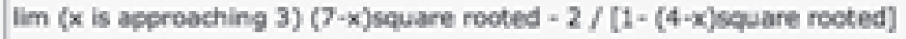

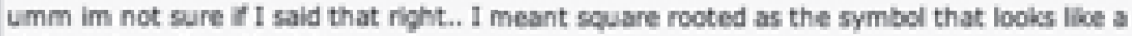
druded gign with a tic at the ond. s.t. Ei the Hember $4,4,45,46$

Wolned! 04 Feb 2604 Fonth mas
Do you mean the following?

$$
\operatorname{limit}_{x \rightarrow 3} \sqrt{7- \pm}-\frac{7}{1-\sqrt{4-1}}
$$

If so, I would suppest rationaling the dencminater and then waluating at $x=3$.

If not, then please review the formatting artides in the "Forum Help" pull-down menu at the very top of the page, and reply with darifoation.

Thank you.

Elis. 


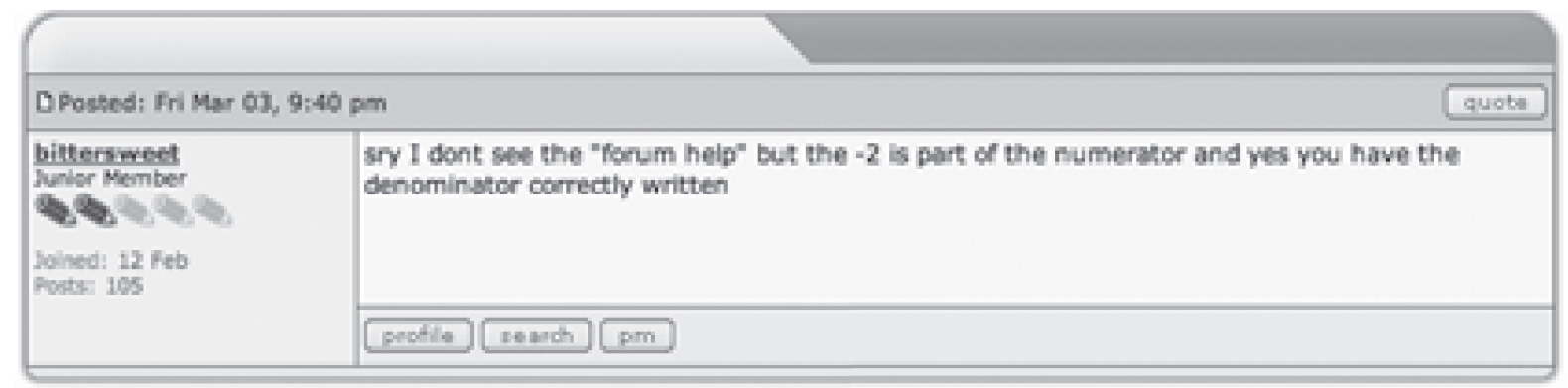

\section{Re: Find the Limit}

DPosted: Fri Mar 63, 0:51 pth

\section{Soraban}

Eive Mamber

towats

Whind: 26 Jan zoos

Fonti: jod

Lesabse Lew wher, in
Hello, bittersweet!

$$
\begin{aligned}
& \text { Quste: } \\
& \lim _{x \rightarrow 3} \frac{\sqrt{7-x}-2}{1-\sqrt{4-x}}
\end{aligned}
$$

We must rationalize the numerator ind the denominator . . .

$$
\begin{aligned}
& \frac{\sqrt{7-x}-2}{1-\sqrt{4}-x} \cdot \frac{\sqrt{7-x}+2}{\sqrt{7-5} \cdot \frac{1+\sqrt{4-x}}{1+\sqrt{4-x}}}=\frac{[(7- \pm)-4](1+\sqrt{4-x})}{[1-(4-5)](\sqrt{7-5}+2)} \\
& =\frac{(3-x)(1+\sqrt{4-x})}{( \pm-3)(\sqrt{7-x+2)}}=\frac{-(x-3)(1+\sqrt{4-x})}{(x-3)(\sqrt{7- \pm}+2)}=-\frac{1+\sqrt{4-x}}{\sqrt{7- \pm+2}} \\
& \text { Therefore: } \lim _{x \rightarrow 3}\left[-\frac{1+\sqrt{4-x}}{\sqrt{7-x+2}}\right]=-\left(\frac{1+\sqrt{1}}{\sqrt{4}+2}\right)=-\frac{2}{4}=-\frac{1}{2}
\end{aligned}
$$

\section{indilt itewh am}

se

Ei te Member

48tates

boined: 04 heb 2oist Fonts: raso

\section{bitteriweet wrote:}

siry I dont see the "Torum help"

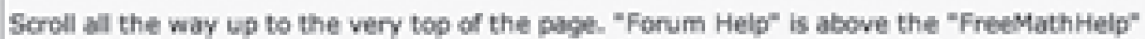
logo, right next to "Forum Index" and "Math Subjects". These are also all vible when you hove rouf browat cpen to the "Pest a foply" bor.

Ela. 
Online Tutoring in the Calculus: Beyond the limit of the limit

Carla van de Sande E Gaea Leinhardt

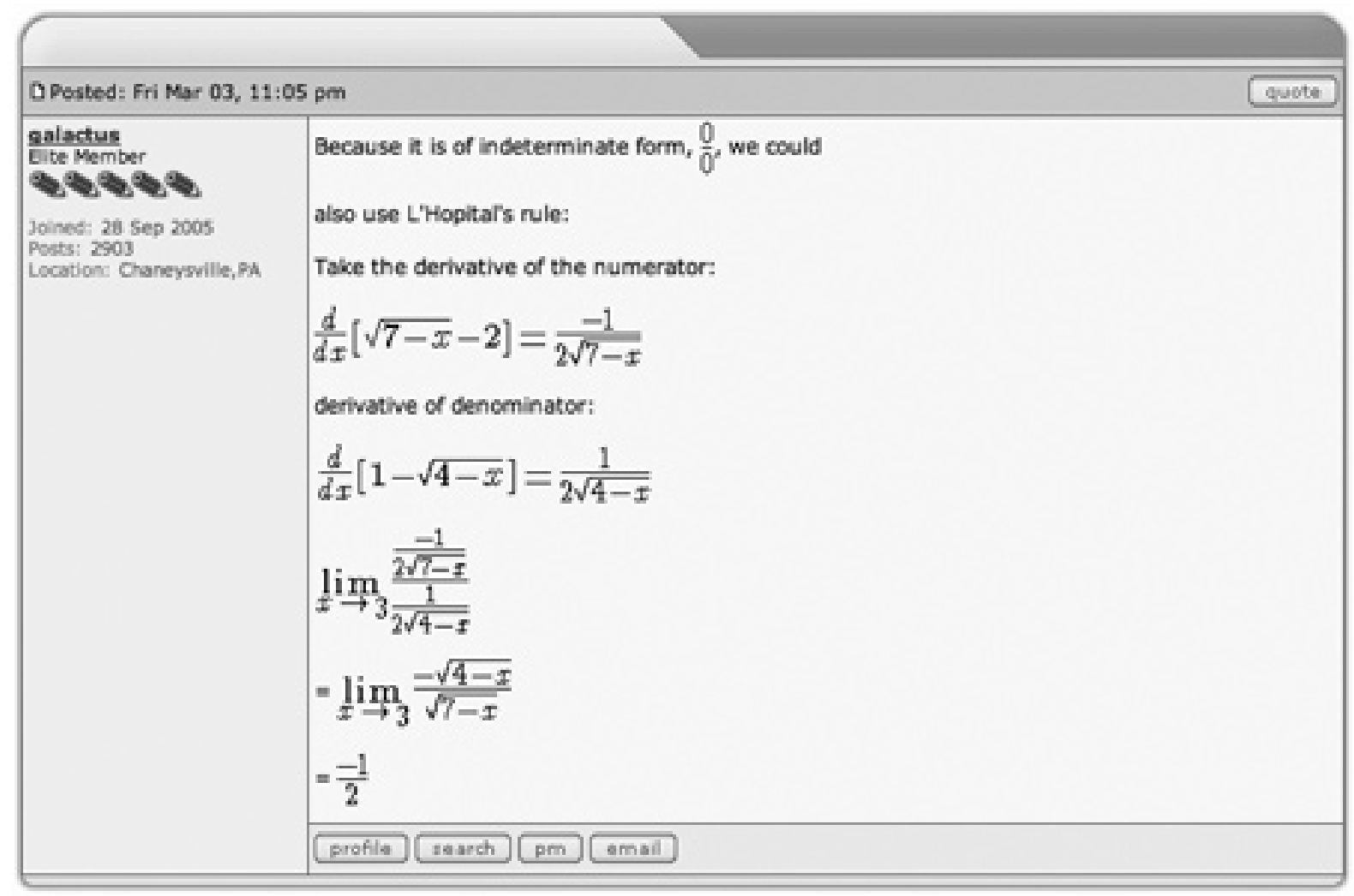

FIGURE 4 Extended online tutoring exchange from FreeMathHelp.com. 
Notice the conversational quality of this exchange that is reflected in the latency of responses. The initial response to the student's query is a request for clarification from SE that comes after only 13 minutes. In this request, SE points the student to the location on the site where information on formatting mathematical text is found. The student replies to this request for clarification after 5 minutes, indicating that he/she is unable to locate the information on formatting and verbally describes the mathematical expression. A second tutor, Soroban, provides help 11 minutes later that emphasizes the necessary mathematical action (rationalizing both the numerator and the denominator). Although the student did not indicate that he/ she had attempted a solution, Soroban is anticipating one plausible initial source of difficulty: while limit exercises involving expressions that require rationalization of the numerator or the denominator are fairly common, this is not the case with expressions that require both. Shortly afterwards, SE follows up on the student's response to finding formatting information with a detailed description of its location on the webpage. Finally, less than 2 hours after the initial query was posted, a third tutor, Galactus, provides an alternative approach (l'Hôpital's rule) together with the mathematical conditions (indeterminate form of type $0 / 0$ ) that permit its application.

The entire discussion that included posing the question, clarifying the expression in question, advice on finding information for formatting mathematical text, and the presentation of two alternative approaches took place in 1 hour and 43 minutes. (For our sample, the average time until the first response was 1 hour and 36 minutes.) This back-and-forth activity is encouraged by the moderation system of the FreeMathHelp.com site: Responses are immediately made available to the participants, with subsequent moderation only occurring if needed. In contrast, the other $\mathrm{SOH}$ site, Cyberpapy. com, introduces a delay in the latency of responses by subjecting them to moderation before they are made available for viewing. This publishing delay may account for the smaller percentage of extended back-and-forth exchanges on this site. In addition, the initial response latency for Cyberpapy.com was much larger than that of FreeMathHelp.com: 17\% of the queries did not generate an initial response authored (much less published) on the same day.
Not only does this delay impact the conversational quality of the communication, but it also fragments the exchanges between participants. If students do not have access to a response, then they may respond by re-posting the same query numerous times. $7 \%$ of the Cyberpapy.com queries in our sample (compared to $1 \%$ for FreeMathHelp.com) were of this type. When a different set of tutors responds to these identical postings, exclusive exchanges on the same query result. That is, the set of tutors responding to one posting may have no knowledge of the responses to the other posting, particularly if they are relying on e-mail confirmation for notification of contributions to a particular exchange.

These analyses of participation codes reveal that different structures encourage different participation patterns. In particular, an $\mathrm{AOH}$ structure promotes brief conversations between single student-tutor pairs, whereas a $\mathrm{SOH}$ structure promotes extended conversations between multiple participants. A delay imposed on the publication of responses in an $\mathrm{SOH}$ structure, however, dampens the effect.

\section{Exchange quality}

Obviously the pattern of participation is not the only important idea to investigate in the online help exchanges. Also important are discussions of mathematical and pedagogical quality. Responses might be brief but of high quality or extended (complex) but of trivial or superficial quality. Another possibility is that these two qualities correspond, so that extended exchanges tend to be more sophisticated with regard to the mathematical and pedagogical treatment of the query. To establish a complete mapping between complexity and quality is beyond the scope of this report, but, to give a flavor of the issue of quality, we explored one site.

Because the FreeMathHelp.com site contains the most interactive exchanges and is conducted in our native language, we chose to focus our analysis of the quality of exchanges on these discussions. The following exchange (Figure 5) is an example of low quality that is devoid of sophisticated mathematical and pedagogical moves. It also received the lowest possible complexity score of 3 : 


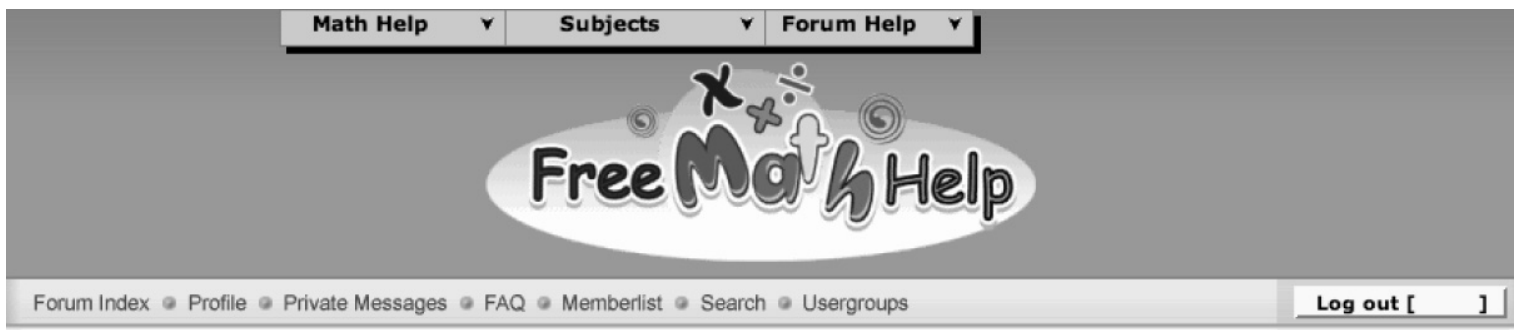

Free Math Help.com - Homework Help! Forum Index " Calculus $" \underline{\operatorname{limit}} \lim (x+8)^{\wedge} 1 / 3-2$ over $x$ as $x$ $\underline{-10}$

Solve your tough algebra problems with Algebra Solved!

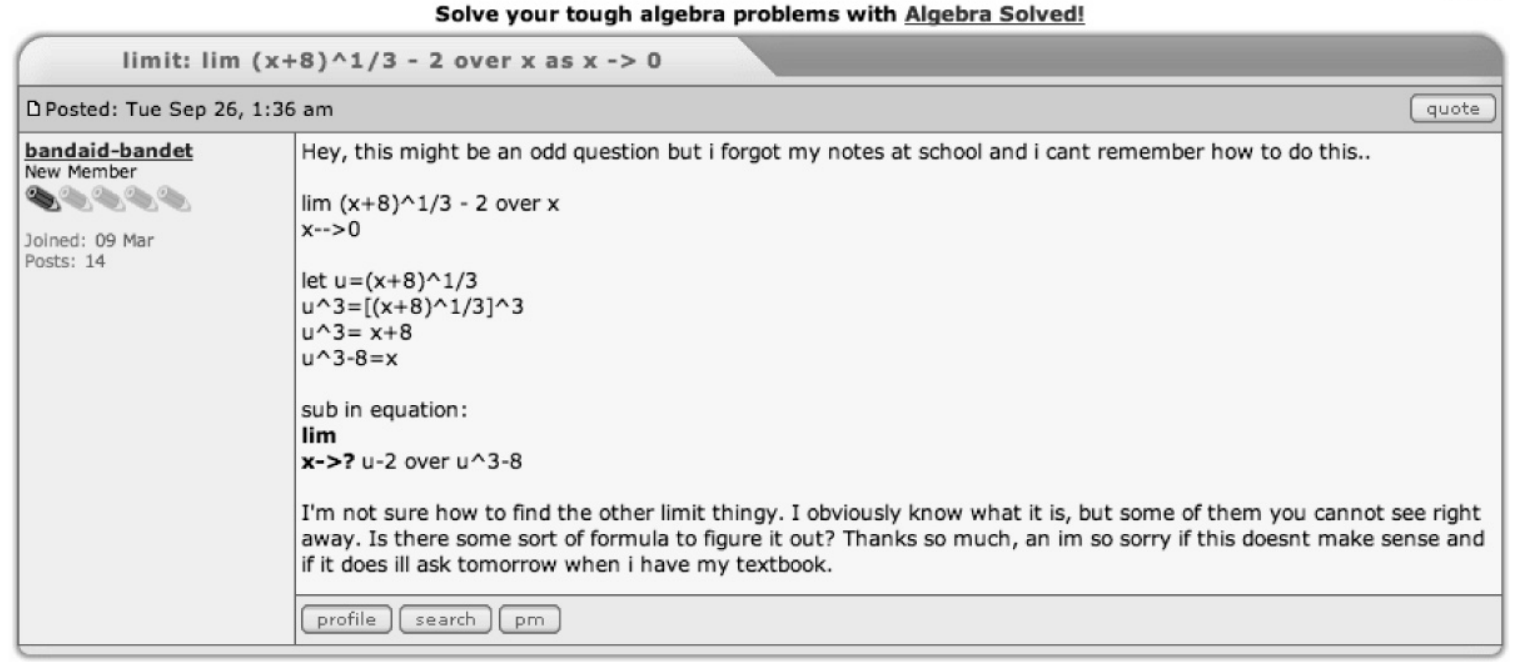

DPosted: Tue Sep 26, 2:47 am
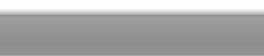

The limit is now " $\mathrm{u}$ approaches 2 ".

FIGURE 5 Low quality online tutoring exchange from FreeMathHelp.com. 
The problem involves a change of variables and the student, Bandaid-bandet, has transformed the expression but expresses uncertainty about how to find the corresponding point of approach. A tutor, Tkhunny, responds with the correct numerical answer for the problem in question but does not explain how or why it is accomplished. In short, there is no explanation proffered although the student has explicitly requested one: "Is there some sort of formula to figure it out?" It is clear from the initial query that Bandaid-bandet does not understand the critical connection between transforming the point of approach and transforming the expression, and there is no evidence that this exchange has been instructional.

At the other extreme, there were exchanges such as the following (Figure 6) that were exemplary and reflected mathematical and pedagogical depth and sophistication. It also was scored as fairly ${ }^{11}$ complex, with a 10 :

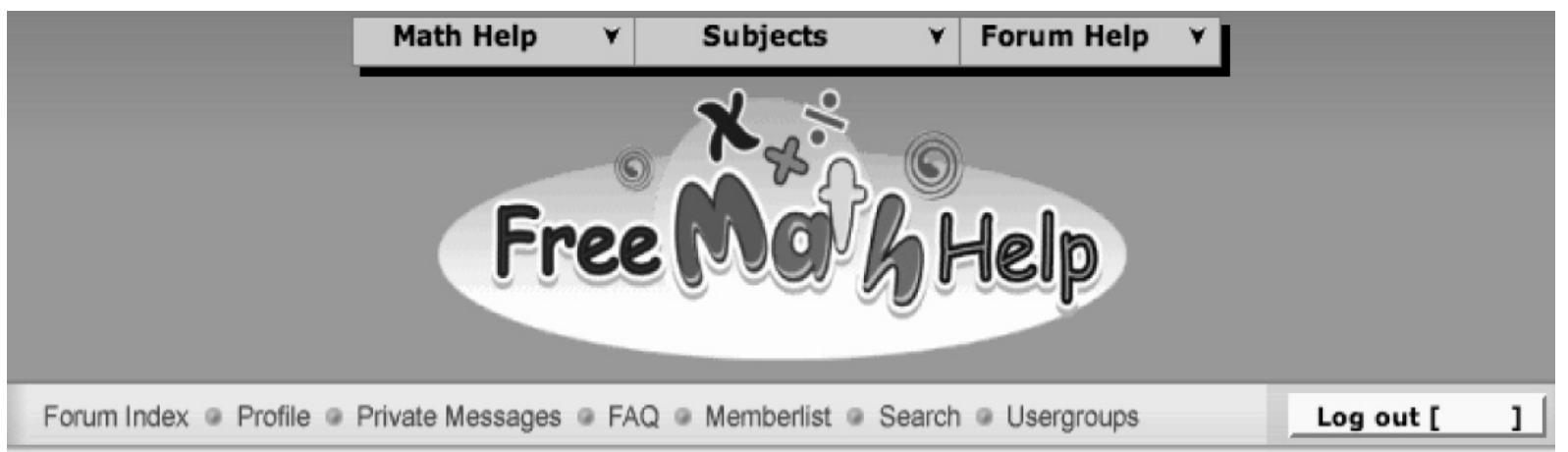

Free Math Help.com - Homework Helpl Forum Index " Calculus " $\underline{\text { limit to }}$ infinity and cos

\section{new topic post reply}

View posts since last visit Vlew your posts View previous topic : : View next topic

\section{Solve your tough algebra problems with Algebra Solved!}

\section{limit to infinity and cos}

CPosted: Wed Feb 28, 1:31 am

\section{BW52}

New Member

Q

Joined: 20 May 2005

Posts: 30
I'm having trouble with one of my questions. I need to find the limit(or find that it does not exist). The question is:

$\lim (t->$ infinity $) \cos \left(t+5 t^{\wedge}(-2)\right)$

Plugging in infinity gets me to cos(infinity), which doesn't really help me much, so I've been trying to get the equation to a format that I can use with little success. I don't think I can use the squeeze theorem, either(but please correct me if I'm wrong).

so far:

$f(t)=\cos \left(t+5\left(1 /\left(t^{\wedge} 2\right)\right)\right)$

$=\cos \left(t+\left(5 /\left(t^{\wedge} 2\right)\right)\right)$

But I can't get anything useful beyond that, as if I try to combine the $t$ and $5 /\left(t^{\wedge} 2\right)$ and divide by the greatest power of $t$ in the denominator, it leads me full circle.

Any help would be appreciated. 
Online Tutoring in the Calculus: Beyond the limit of the Limit

Carla van de Sande E Gaea Leinhardt

D Posted: Wed Feb 28, 3:48 am

skeeter

Senior Member

\& 2 ? 2

Joined: $16 \mathrm{Dec} 2005$

Posts: 1648

Location: Fort Worth, TX o.k. answer a more simple problem ... does the following limit exist ?

$\lim _{x \rightarrow \infty} \cos (x)$

why or why not?

C Posted: Wed Feb 28, 4:24 am

quote

\section{BW52}

New Member

a 250 es

Joined: 20 May 2005

Posts: 30
No, since cos graphs go up and down between -1 and 1 throughout the graph. It won't be closer to either value or to a value in between at infinity.

And replacing $x$ with $t+5 t^{\wedge}-2$ would get us the same answer to the previous question, correct? (although that would do strange things to the $x$->infinity, wouldn't it?)

profile search $\mathrm{pm}$

\section{Posted: Wed Feb 28, 2:05 pm}

skeeter

Senior Member

$\rightarrow ? \rightarrow$ ?

Joined: 16 Dec 2005

Posts: 1648

Location: Fort Worth, TX bingo.

however, no strange behavior $\ldots \cos \left(t+5 / t^{2}\right)$ would behave pretty much the same as $\cos (x)$ as both $x$ and $t->$ infinity.

why?

profile search $\mathrm{pm}$




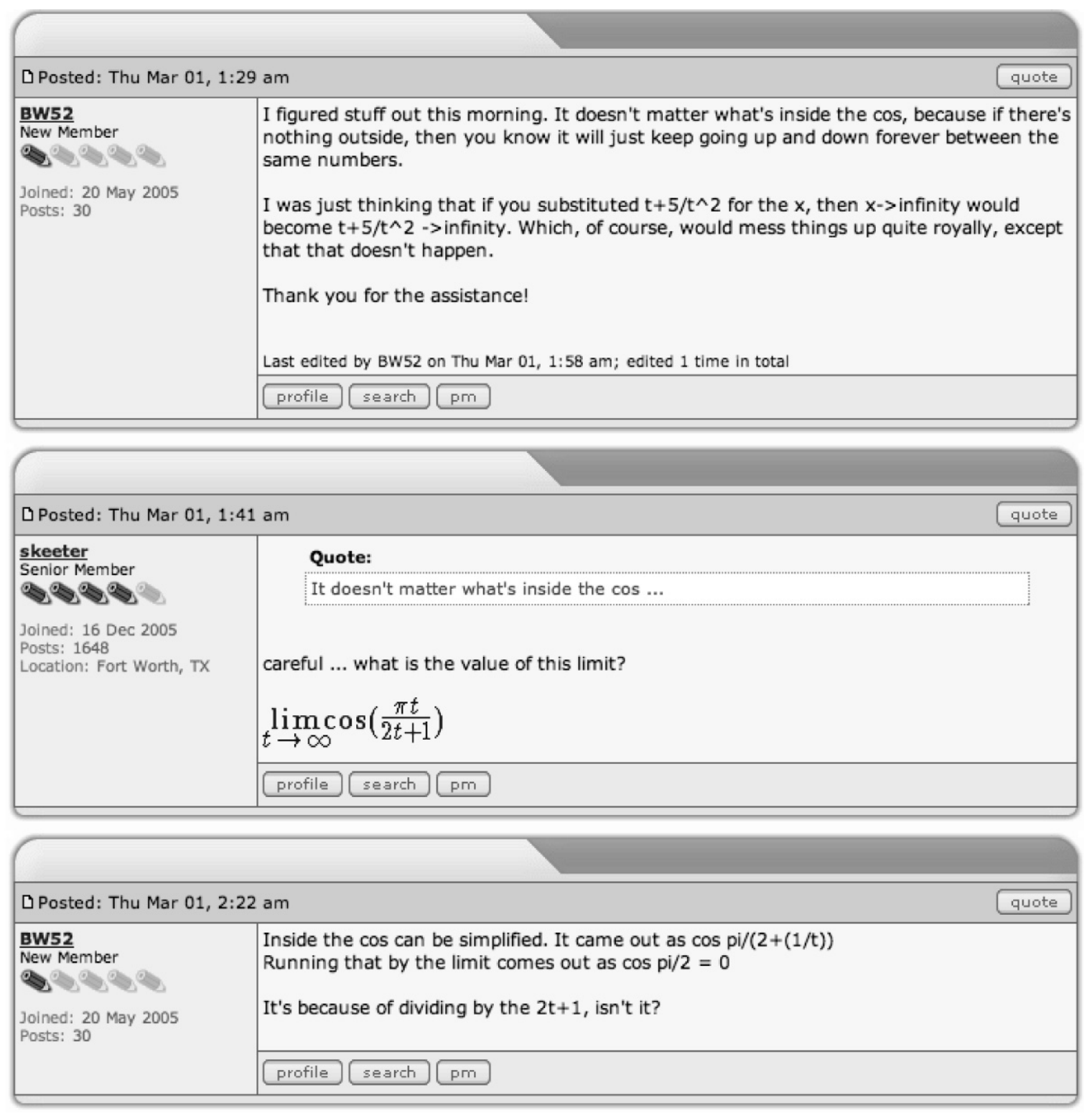

FIGURE 6 Exemplary online tutoring exchange from FreeMathHelp.com.

The student, Bw52, posts a request involving the computation of the limit approaching infinity of a composition of two functions, $\cos (t)$ and $\mathrm{t}+5 \mathrm{t}^{-2} \mathrm{Bw} 52$ indicates that he/she has unsuccessfully attempted to transform the inner function, $\mathrm{t}+5 \mathrm{t}^{-2}$, as an initial approach to solving the problem. A tutor, Skeeter, responds by posing a simpler problem for consideration: $\lim _{x \rightarrow \infty} \cos (\mathrm{x})$. The simplification of a problem is a key mathematical move as identified by Pólya (1945) and also functions as a pedagogical move (Leinhardt \& Schwarz, 1997) that switches the focus of the student's attention (from the behavior of the inner function to that of the outer function). Bw52 reasons through this simpler problem and connects it back to the original expression: "And replacing $\mathrm{x}$ with $\mathrm{t}+5^{\wedge}-2$ would get us the same answer to the previous question, correct?" However, the phrasing of this conclusion as a question reflects uncertainty, as does the accompanying parenthetical remark, "(although that would do strange things to the $\mathrm{x}->$ infinity, wouldn't it?)" Skeeter responds by affirming Bw52's conclusion ("bingo.") and addresses Bw52's concern that the original expression may behave differently than the simpler one: "however, no strange 
behavior ... $\cos (t+5 / t 2)$ would behave pretty much the same as $\cos (\mathrm{x})$." Skeeter concludes this remark by asking Bw52 to explain why this statement is valid, a conversational move inviting the student to take another turn in the exchange and a pedagogical move supporting self-explanation. Bw52 accepts this invitation and produces an explanation that references the bounded property of the cosine function: "It doesn't matter what's inside the cos, because if there's nothing outside, then you know it will just keep going up and down forever between the same numbers." This explanation, however, shows that Bw52 has over-generalized the conclusion that can be drawn in this instance. The feature of the problem that was preserved in the reduction was that the inner function must approach infinity in both cases. Although Bw52 indicates that he/she is now satisfied with the exchange and feels that the problem is resolved (ending this posting with an expression of appreciation for the assistance provided), Skeeter reopens the exchange with a warning ("careful...") that is supported by the framing of a counterexample ("what is the value of this limit? $\lim _{t \rightarrow \infty} \cos \left(\frac{\pi t}{2 t+1}\right)$ ").

The development of a counterexample is another key mathematical move (Rissland, 1989), and one that functions pedagogically as Socratic dialogue. Through answering this question, the student is confronted with a logical fallacy in his/her reasoning. The final posting in this exchange indicates that these mathematical and pedagogical moves were productive. Bw52 reasons through the counterexample, produces a numerical answer that is not supported by the previous (overly general) claim ( 0 versus 'does not exist'), and pinpoints the difference between this case and the prior expression ("It's because of dividing by the $2 t+1$, isn't it?"). The evident productivity of the exchange may account for the fact that, although Bw52 once again hedges, Skeeter does not reenter the exchange. Given the attention and response to incorrect conclusions in the discussion, the implicit message to Bw52 is that he/she has now arrived at a correct conclusion.

These two examples, collected from the same site, illustrate the difference in quality that characterizes open online tutoring exchanges. Exchanges can be sparse fragments of mathematical information (as in the first example) or elaborated complete mathematical discussions in which sophisticated pedagogical elements are present (as in the second example). There also seems to be a positive relationship between our measures of complexity (based on number of participants and number of turns in the exchange) and quality (based on the extent of mathematical and pedagogical sophistication). Exchanges that involve few participants and contributions are often trivial communications of mathematical information that are devoid of complex pedagogical moves. On the other hand, exchanges that involve multiple participants and contributions tend to be imbued with mathematical issues and manifest intricate pedagogical moves.

\section{Community}

In addition to looking at the complexity and quality of online tutoring, we have also noted that the sites exhibit several features that are characteristic of community. That is, individuals with no connection or affiliation to one another outside of interacting in these forums have joined together for the purpose of receiving and providing mathematical tutoring support. As discussed previously, the group of tutors constitutes the core of the community although students participate in ways consistent with community membership. In order to provide a sense of how these online sites function as communities, we discuss the manifestation of each characteristic in turn:

\section{Participants share common explicit and implicit goals}

All three of the online tutoring sites exist for the explicit purpose of providing students with accurate mathematical help. In addition, MathNerds. com $(\mathrm{AOH})$ makes response timing an explicit goal by implementing a system in which there is a specified time period for the initial response to a query. Providing responses in a timely manner was also a goal of the $\mathrm{SOH}$ sites but as an implicit understanding amongst participants. This phenomenon was particularly evident in the FreeMathHelp.com site as tutors often exchanged light-hearted banter with one another about the speed of response. For example, when two tutors responded to a query virtually simultaneously (so that the postings were published just minutes apart), the second tutor edited his/her posting and appended the following: "You 
ornery Soroban, you beat me. Oh well, my approach is slightly different."

Another goal of the online help sites is to encourage students to communicate mathematics clearly. Tutors in all three sites frequently commented on the ambiguity and lack of clarity in the framing of the query. The neglect of parentheses, in particular, was a frequent culprit. Students often wrote mathematical expressions in a horizontal orientation and did not use parentheses to indicate the grouping of terms. Although it was evident that tutors could generally infer what the intended query was, they still chided students. In an exchange from Cyberpapy. com (Figure 3), the student, Alice, seeks help on showing that the limit as $\mathrm{x}$ approaches 2 of the expression, $x^{2}-x-2 / x-2$ is 3 . As written, this expression would be interpreted as $x^{2}-x-\frac{2}{x}-2$. However, there are several clues that the intended expression is actually $\left(x^{2}-x-2\right) /(x-2)$ : the answer that Alice provided (namely, 3) corresponds to the limit of this expression, Alice expressed her inability to write the function in a different form (a move that would not otherwise be necessary), and, finally, this interpretation places the exercise in a traditional class of limit problems (functions with a removable discontinuity). The first two tutors that respond, Dd and Katy, both admonish Alice for the lack of clarity: "Il y a une erreur dans l'énonce" and "Attention à l'écriture !..." Three more tutors (Mimi, VI1378, and Chamonix) respond with advice based on a non-literal interpretation of the expression (that is, the intended versus the actual).

In face-to-face encounters, chiding or admonishing is considered a face-threatening act and, as such, a violation of universal rules of politeness (Brown \& Levinson, 1987). However, these maxims do not necessarily extend to online interactions, where face-threatening acts are tempered by physical distance, written versus spoken communication, and anonymity. This is an unique property of online tutoring since adhering to conversational maxims and politeness strategies (such as refraining from critique) can impede pedagogical goals (such as perspicuity) (Person, Kreuz, Zwaan, \& Graesser, 1995). The outcome of the above tutoring exchange illustrates how online interactions can succeed in mitigating this tension. The student, Alice, reposts the query the following day (perhaps after receiving only the first response due to the publishing delay) with an accurate formulation of the query that includes appropriate parentheses (Figure 7). Thus, the violation of politeness principles contributed to the productiveness of the exchange and the community goal promoting clear and accurate mathematical formulations.

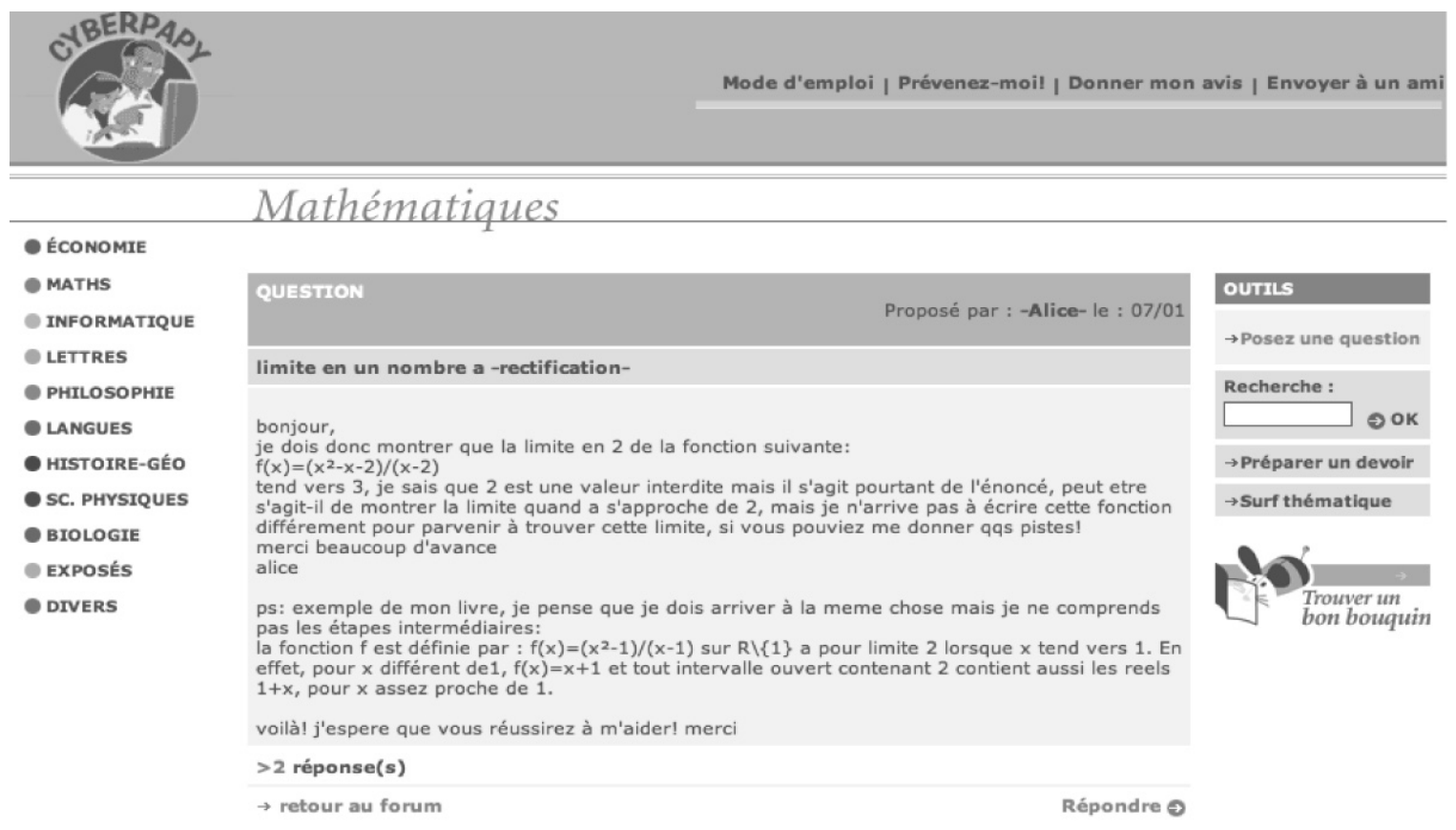




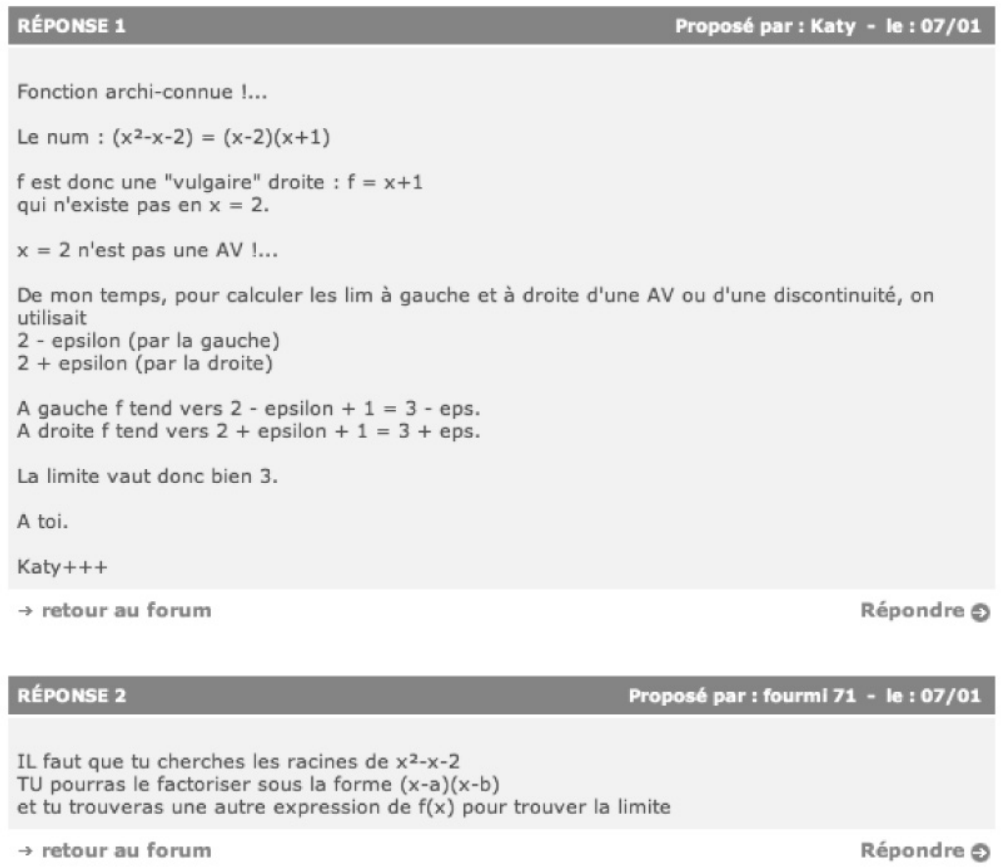

FIGURE 7 Cyberpapy.com exchange following violation of politeness principles.

Participants have an accessible physical or virtual location in which they meet.

Online help sites are virtual locations that are hosted on a server and participants have access to these sites through a registration system. When members participate, their contributions are indexed by date and/or time, in some ways analogous to the societal practice of leaving a calling card. FreeMathHelp.com has an added feature that provides logged on participants a list of other participants who are currently visiting the site. This opportunity for effectively chatting with other members who are currently engaged in the same activity increases the sense of community in this site.

The costs of acquiring and maintaining an online help site are low, especially compared to face-to-face tutoring communities. Aside from the administrative costs (associated with performing upgrades, repairing technical glitches, and moderating), there are few expenses. The sites depend on benevolence (such as Foundation Boulanger) or advertising ${ }^{12}$ to supply their financial needs and rely on search engines and reputation to broadcast their presence. The amount of participation in the online sites we investigated is evidence that these locations are very accessible to the student population ("FreeMathHelp.com served
$1,891,472$ pages to 616,839 visitors last year and another million pages to search engine robots and the like." [T. Wilcox, personal communication, June $9,2007]$.

Participants identify themselves as members of the community.

In addition to sharing common goals and meeting together at a designated location, participants in the online help sites treat fellow members as colleagues rather than strangers or mere associates. For example, members reference one another by name as when Chamonix (Figure 3) elaborated on the posting of another tutor, Katy: "Katy a raison, mais lorsqu'on parle de limite on ne se place pas en $x=2$, seulement très près." The sense of community is also evident when tutors reference one another in ways that demonstrate an awareness of fellow members as a resource. For instance, when a FreeMathHelp. com tutor provided a solution that relied on l'Hôpital's rule, he qualified his/her posting with the following appeal to three fellow tutors by name, extended to other participating tutors: "I don't like to use L'Hopital ${ }^{13}$ unless I have to. I think I'll use it on this one. Perhaps pka, Soroban, Skeeter, or 
someone will be along with a non-L'Hopital method. It's even precarious with L'Hopital."

As well as speaking about one another, participants in online help sites speak to one another, addressing each other by "name." In the following example (Figure 8) from FreeMathHelp.com, a tutor, Galactus, compliments another tutor, Pka, on an alternative approach to the problem that does not rely on l'Hôpital's rule.
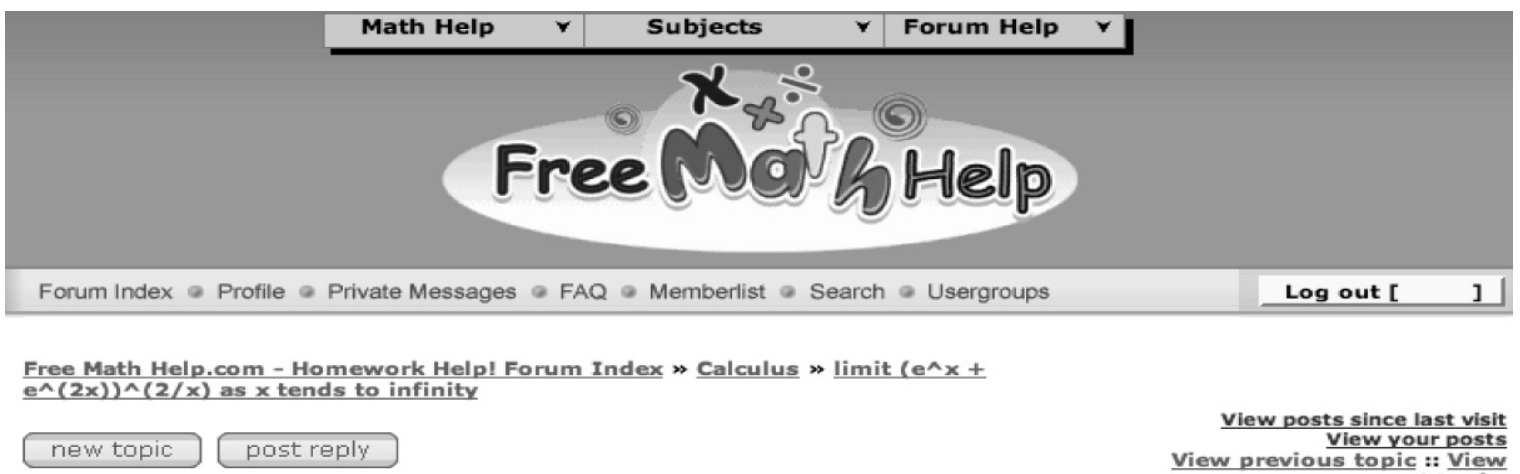

Solve your tough algebra problems with Algebra Solved!

\begin{tabular}{|c|c|c|}
\hline \multicolumn{2}{|c|}{ D Posted: Fri Jun 09, 5:15 pm } & quote \\
\hline \multirow{2}{*}{$\begin{array}{l}\text { turkey } \\
\text { New Member } \\
\text { Joined: } 09 \text { Jun } \\
\text { Posts: } 3\end{array}$} & $\lim _{x \rightarrow \text { infinity }}\left(e^{\wedge} x+e^{\wedge}(2 x)\right) \wedge(2 / x)$ & \\
\hline & profile search $\mathrm{pm}$ & \\
\hline
\end{tabular}

\begin{tabular}{|c|c|c|}
\hline \multicolumn{2}{|c|}{ 口 Posted: Fri Jun 09, 5:46 pm } & quote \\
\hline \multirow[t]{2}{*}{$\begin{array}{l}\text { galactus } \\
\text { Elite Member } \\
\text { Joined: } 28 \text { Sep 2005 } \\
\text { Posts: } 2896 \\
\text { Location: Chaneysville, PA }\end{array}$} & $\begin{array}{l}\lim _{x \rightarrow \infty}\left(e^{x}+e^{2 x}\right)^{\frac{2}{x}} \\
\text { Rewrite: } \\
\lim _{x \rightarrow \infty} e^{\frac{2}{x} \ln \left(e^{x}+e^{2 x}\right)} \\
e^{\lim _{x \rightarrow \infty}\left(\frac{2}{x} \ln \left(e^{x}+e^{2 x}\right)\right)} \\
e^{2} \lim _{x \rightarrow \infty} \frac{\ln \left(e^{x}+e^{2 x}\right)}{x} \\
\text { Now, try L'Hopital's rule: } \\
\ln \left(e^{x}+e^{2 x}\right) d x=2-\frac{1}{e^{x}+1} \\
e^{2} \lim _{x \rightarrow \infty} \frac{2-\frac{1}{e^{x}+1}}{1} \\
\text { As can be seen, the limit of } 2-\frac{1}{e^{x}+1} \rightarrow 2 \\
\text { So, we have: } \\
e^{2(2)}=e^{4}\end{array}$ & \\
\hline & profile search pm email & \\
\hline
\end{tabular}




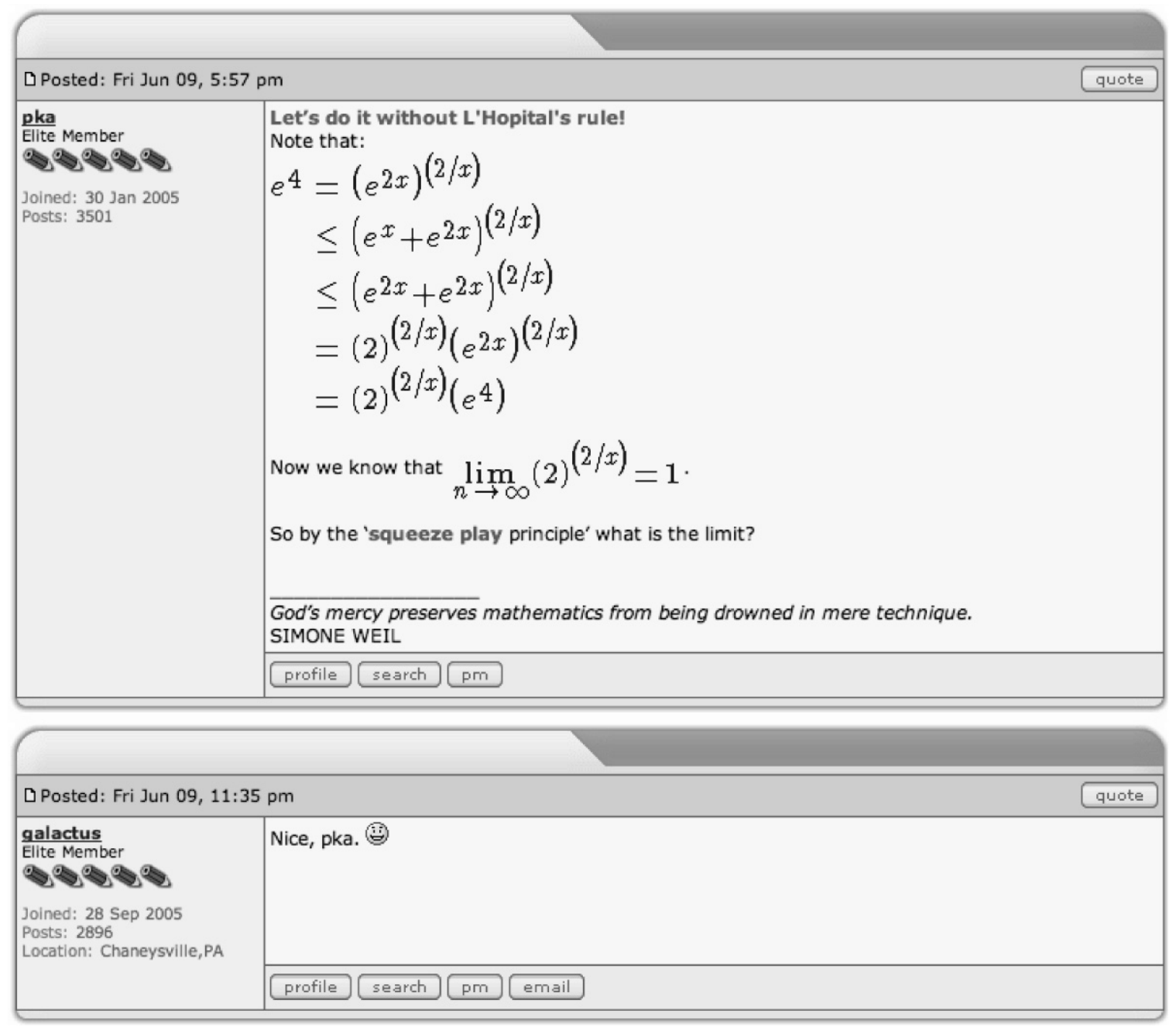

FIGURE 8 Tutors addressing one another by name in FreeMathHelp.com.

This exchange illustrates how tutors attend to the contributions of other tutors in open online help forums and demonstrates a "side-benefit" of this venue. In addition to supporting students (the intended population), online tutoring sites can also be instructive for tutors. Through Pka's contribution, Galactus learns a novel way of approaching the problem mathematically. The "smiley face" emoticon that is part of Galactus's compliment is indicative of the enthusiasm for novel approaches and perspectives in these online help sites.

What is more, this instructive potential for tutors extends beyond learning mathematics to becoming cognizant of pedagogical issues. When a FreeMathHelp tutor used the expression $\tan ^{-1}(\infty)$ in reply to a student, a fellow tutor responded with: "PLEASE, PLEASE, PLEASE NEVER write. $\tan ^{-1}(\infty)=\frac{\pi}{2} . \infty$ is NOT A NUMBER.

$\lim _{x \rightarrow-\infty} \arctan (x)=\frac{-\pi}{2}$." This emphatic plea for precision while tutoring mathematics concerns a common student misunderstanding, namely the treatment of the infinity concept as a number. Although it is not uncommon for mathematicians to refer casually to the limit of a function as "infinity" (as though infinity were a 'point' of approach), this is presumably accompanied by an implicit formal understanding of the underlying meaning. Students, on the other hand, are apt to over-generalize based on such linguistic expressions and, as a consequence, treat infinity as 
a number that is subject to the laws of arithmetic, concluding, for instance, that $\infty-\infty=0$ or $\infty / \infty=1$ The response to this plea was an apology from the offending tutor ("Sorry 1 ") and demonstrated the way pedagogical critique from fellow members in these sites is generally received.

Although there is much less evidence of studentstudent and student-tutor familiarity, there is unquestionably a sense in which students treat the online help sites as a community. They refer in plural to tutors when acknowledging them ("Thanks guys. You guys are truely helpful" and also address them by name ("Merci beaucoup a tous les deux... Malheureusement non, je n'ai pas vu cette méthode pour utiliser le théorème des gendarmes kris, ce qui me posait problème...Merci diabolo car je n'avais pas pensé a remplacer $\ln (1+\mathrm{X})$ par $\mathrm{X}$ tout court...Bonne fêtes de fin d'année !"). In general, students seem appreciative of these open online communities that provide them with free and timely quality mathematical help.

Finally, there is a sense in which each online site is itself a member of a larger community of help sites. As noted earlier, several tutors participate using the same "handle" in multiple online help sites. Although individuals may take on different roles in different communities (for example, SE acts as a moderator in one site but exclusively as a tutor in another), the cross-participation functions as a common thread through the larger community. The communities also refer to one another and inform students of the presence and location of other help sites. FreeMathHelp. com includes links to other help sites (including MathNerds.com).

\section{Participants assume responsibility for participation.}

We have discovered that participants, both tutors and students, in these online help sites assume responsibility for participation in numerous ways. Tutors collaborate with one another to provide quality and timely mathematical help, and students collaborate in the problem-solving activity. The collaboration between tutors takes on several forms that manifest themselves within a single tutoring exchange (sharing roles, taking turns and introducing alternative approaches) as well as across tutoring exchanges (sharing the load and distributing expertise). Students' collaborative efforts include the contribution of mathematical problem-solving steps and the questioning of others. Although by no means an exhaustive list, the following are examples of ways in which responsibility is assumed in the online help sites:

i. Roles. In addition to demonstrating how an $\mathrm{SOH}$ structure fosters extended discussions between multiple participants, the exchange in Figure 4 demonstrates how tutors may collaborate by taking on different roles in a single exchange. Here, each of the three tutors plays a different role in the tutoring activity: SE presses for clarity in the formulation of the query ("Do you mean the following? [...] If not, then please review the formatting articles in the "Forum Help" pull-down menu at the very top of the page, and reply with clarification."), Soroban provides help in the form of a worked solution ("We must rationalize the numerator and the denominator ...") , and Galactus provides an alternative approach for solving the problem ("Because it is of indeterminate form, $\frac{0}{0}$, we could also use L'Hopital's rule"). The result of this spontaneous and encompassing collaborative effort is that the student is tutored with respect to proper mathematical notation, mathematical procedures, as well as mathematical practices (specifically, mathematics as a domain in which multiple approaches lead to the same result).

ii. Turns. Another way in which tutors collaborate is by taking (conversational) turns in an exchange, for example by answering questions that are directed at another. In the following exchange (Figure 9) from Cyberpapy.com, a tutor, La Flégère, responds to a query that the student, Flore/Gimoka ${ }^{14}$, poses to the first tutor, Papi Gérard. 
Online Tutoring in the Calculus: Beyond the limit of the limit

Carla van de Sande E Gaea Leinhardt

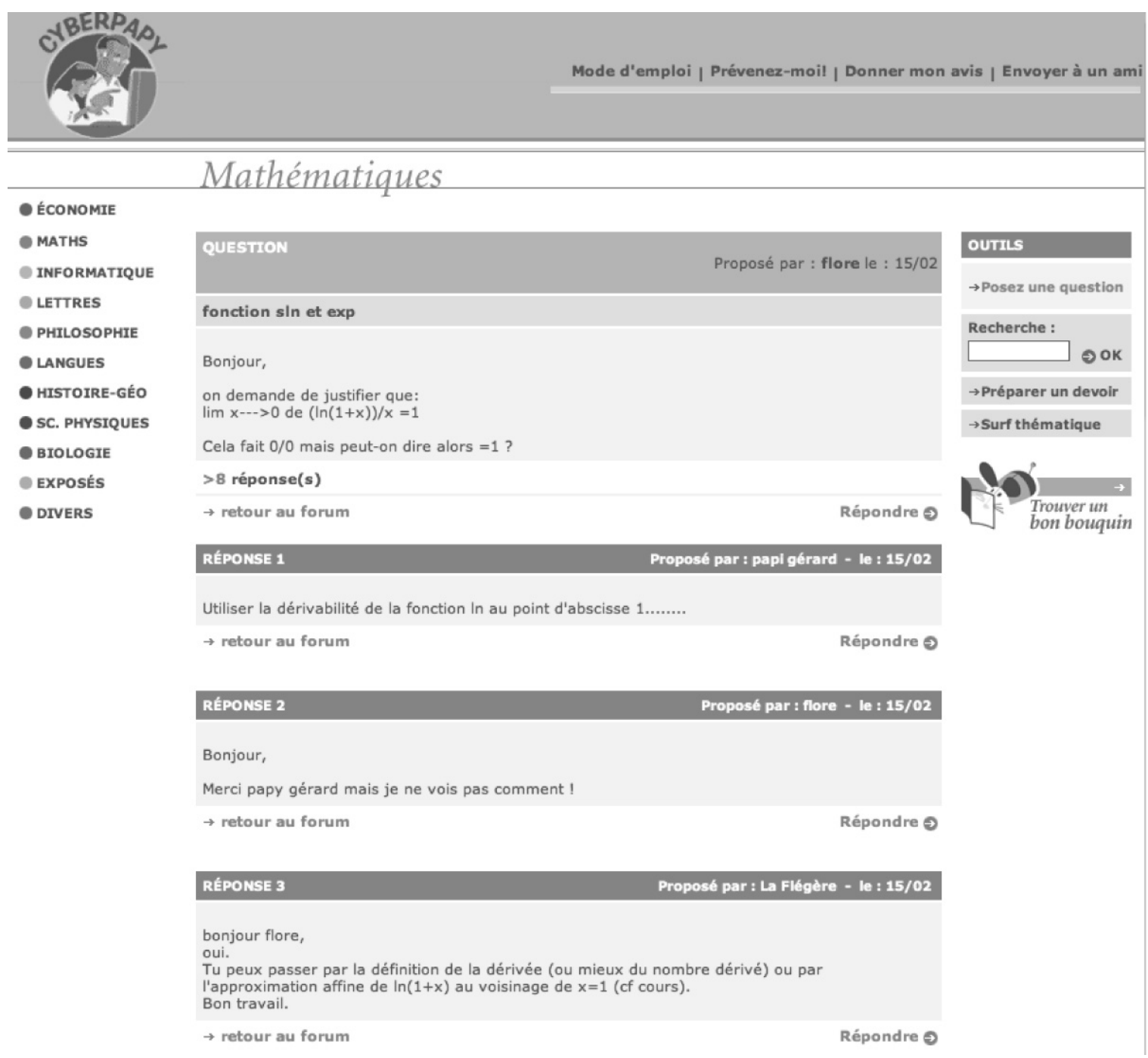


bonjour,

mais papy gérard et la Flégère,

je vois bien qu'en posant $y=1+x$

on obtient la dérivée

$(\ln y-\ln 1) /(y-1)$ pour $y->1$

mais comment prouver que ...>1

$\rightarrow$ retour au forum

Répondre $\Theta$

Bonjour,

Je pense avoir compris!

La dérivée de $\ln y=1 / y$ donc $=1$ pour $y=1$

Merci à tous

$\rightarrow$ retour au forum

Répondre $\oplus$

\section{RÉponse 6}

Bonjour Flore et gimoka,

pour une fois je détaille:

a) Méthode du nombre dérivé.

On appelle nombre dérivé en $x=a$ de $\ln (x)$ la limite quand $x$ tend vers 0 de

$(\ln (a+x)-\ln (a)) /(x+a-a)$

Si je fais $a=1, j$ 'ai bien

$\mathrm{L}=$ limite $\mathrm{x} \rightarrow 00$ de $\ln (1+\mathrm{x}) / \mathrm{x}$

Par ailleurs, chacun sait, après avoir appris le cours, que $(\ln (x))^{\prime}=1 / x$ et donc que

en $x=1 \ln (x)^{\prime}=1 / 1=1=L$

CQFD.

b)Méthode de l'approximation affine.

$f(a+h)=f(a)+h * f^{\prime}(a)+h *$ epsilon $(h)$

epsilon( $h$ ) est une fonction qui tend vers zéro avec $h$, petit écart de $x$ autour de $a$.

Donc pour $h$ très petit

$f(a+h) \sim f(a)+h * f^{\prime}(a)(1)$

C'est l'approximation affine, puisqu'on assimile localement $f(x)$ à un segment de droite.

Faisons $f=\ln , a=1$ et $h=x$.

Quand $x$ tend vers 0

$\ln (1+x) \sim x^{*} 1 / 1$

Donc

$\ln (1+x) / x->1$ CQFD

NB:

La première méthode n'est pas tj employable.

Je vous ai donc donné les deux.

Dans des cas cas retors, il faut développer plus "loin".

$f(a+h) \sim f(a)+h * f^{\prime}(a)+h \wedge 2 / 2 * f^{\prime \prime}(a)(2)$

$f(a+h) \sim f(a)+h * f^{\prime}(a)+h^{\wedge} 2 / 2 * f^{\prime \prime}(a)(2)$
On assimile $f(x)$ à un arc de parabole.

Celà ne fait pas partie du cours. Certains profs le font découvrir en exercice, surtout pour montrer l'évolution de $\cos (x)$ et $\sin (x)$ pour $x$ petit.

Bon travail. Aimez les maths !

$\rightarrow$ retour au forum

Répondre $\Theta$

bonjour,

Merci, c'est plus net dans ma tete maintenant

@+

$\rightarrow$ retour au forum

Répondre $\Theta$

La méthode la plus rapide, dans la mesure où on connaît le développement en série de la fonction In, est d'écrire:

$\ln (1+x)=x-(1 / 2) x^{2}+(1 / 3) x^{\wedge} 3-1 / 4 x^{\wedge} 4+.$.

On divise par $x$

La limite vaut donc 1.

Katy+++

$\rightarrow$ retour au forum

Répondre $\Theta$

FIGURE 9 Example of turn-taking from Cyberpapy.com. 
Carla van de Sande E Gaea Leinhardt

When Flore/Gimoka expresses uncertainty regarding the hint provided by Papi Gérard ("Merci papy gérard mais je ne vois pas comment !"), La Flégère responds with an affirmation ("oui.") and a revoicing of the approach ("Tu peux passer par la definition de la derivée"), accompanied by an additional approach ("ou par l'approximation affine de $\ln (1+x)$ au voisinage de $x=1$ "). In this exchange a sense of community is also evident from members referring to one another by name. iii. Load-sharing (with exchanges). Although the majority of the queries involve a single problem, it is not unusual for students to pose a set of problems simultaneously. In these instances, tutors may collaborate by dividing up the work, with different tutors taking on each problem. In the following exchange (Figure 10) from FreeMathHelp.com involving two problems, Pka answers the first question and Soroban answers the one remaining.

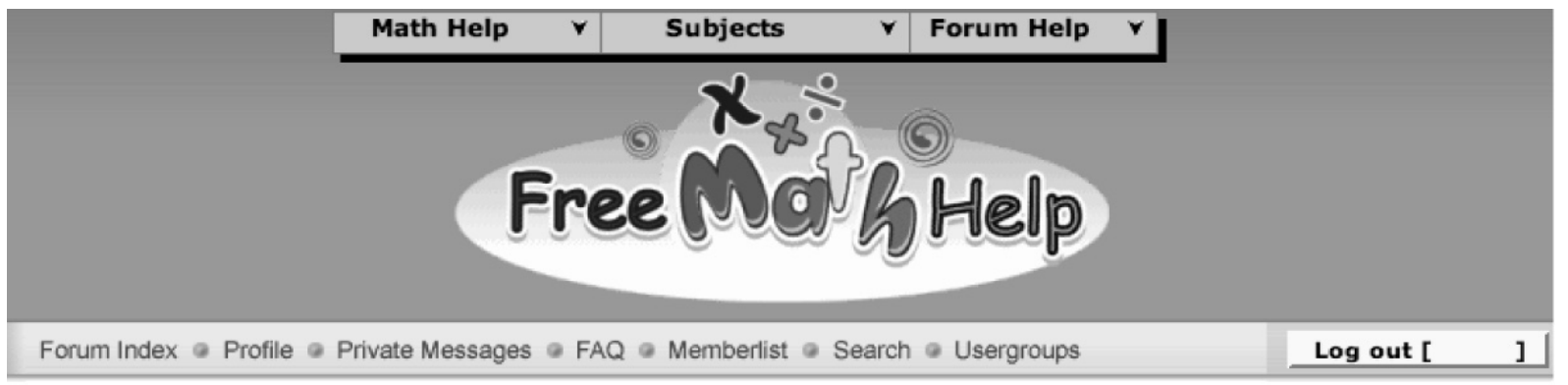

Free Math Help.com - Homework Help! Forum Index " Calculus " L'Hospital's Rule

\section{Solve your tough algebra problems with Algebra Solved!}

\section{L'Hospital's Rule}

D Posted: Sun May 07, 7:40 pm

\begin{tabular}{|c|c|}
\hline \multirow[t]{2}{*}{$\begin{array}{l}\text { elcatracho } \\
\text { New Member } \\
\text { Joined: } 09 \text { Aug } 2005 \\
\text { Posts: } 25\end{array}$} & $\begin{array}{l}\text { Hello I had two questions about problems that use L'Hospital's rule. The instructions are find } \\
\text { the indicated limit. Use L'Hospital's rule IF necesary. the first question is lim of } x^{\wedge} x \text { as } x \text { gets } \\
\text { closer to } 0+\text {. So far I have done } x \text { times Inx. I dont know what to do from here. The next } \\
\text { problem is lim of } \operatorname{Sin}(x)^{\wedge}(\tan (x)) \text { as } x \text { approaches pi/2-. Again, so far is did tan }(x) \text { times Sin (x) } \\
\text { but i dont know what to do from there. When I did it on the calculator i got } 1 \text { for both answers } \\
\text { but I'd really like to know how to do it by hand. Thank You:) }\end{array}$ \\
\hline & profile \\
\hline
\end{tabular}

\begin{tabular}{|c|c|c|}
\hline \multicolumn{2}{|c|}{ D Posted: Sun May 07, 7:55 pm } & quote \\
\hline \multirow[t]{3}{*}{$\begin{array}{l}\text { pka } \\
\text { Elite Member } \\
\text { Joined: } 30 \text { Jan } 2005 \\
\text { Posts: } 3502\end{array}$} & \multicolumn{2}{|l|}{$\begin{array}{l}y=x^{x} \Rightarrow \ln (y)=x \ln (x) \\
\lim _{x \rightarrow 0^{+}} \ln (y)=\lim _{x \rightarrow 0^{+}} \frac{\ln (x)}{\frac{1}{x}}=\lim _{x \rightarrow 0^{+}} \frac{\frac{1}{x}}{x^{2}}=0 \\
\lim _{x \rightarrow 0^{+}} x^{x}=\lim _{x \rightarrow 0^{+}} e^{\ln (y)}=e^{x \rightarrow 0^{+}} \frac{\ln (y)}{=1}\end{array}$} \\
\hline & \multicolumn{2}{|l|}{$\begin{array}{l}\text { God's mercy preserves mathematics from being drowned in mere technique. } \\
\text { SIMONE WEIL }\end{array}$} \\
\hline & profile search $\mathrm{pm}$ & \\
\hline
\end{tabular}




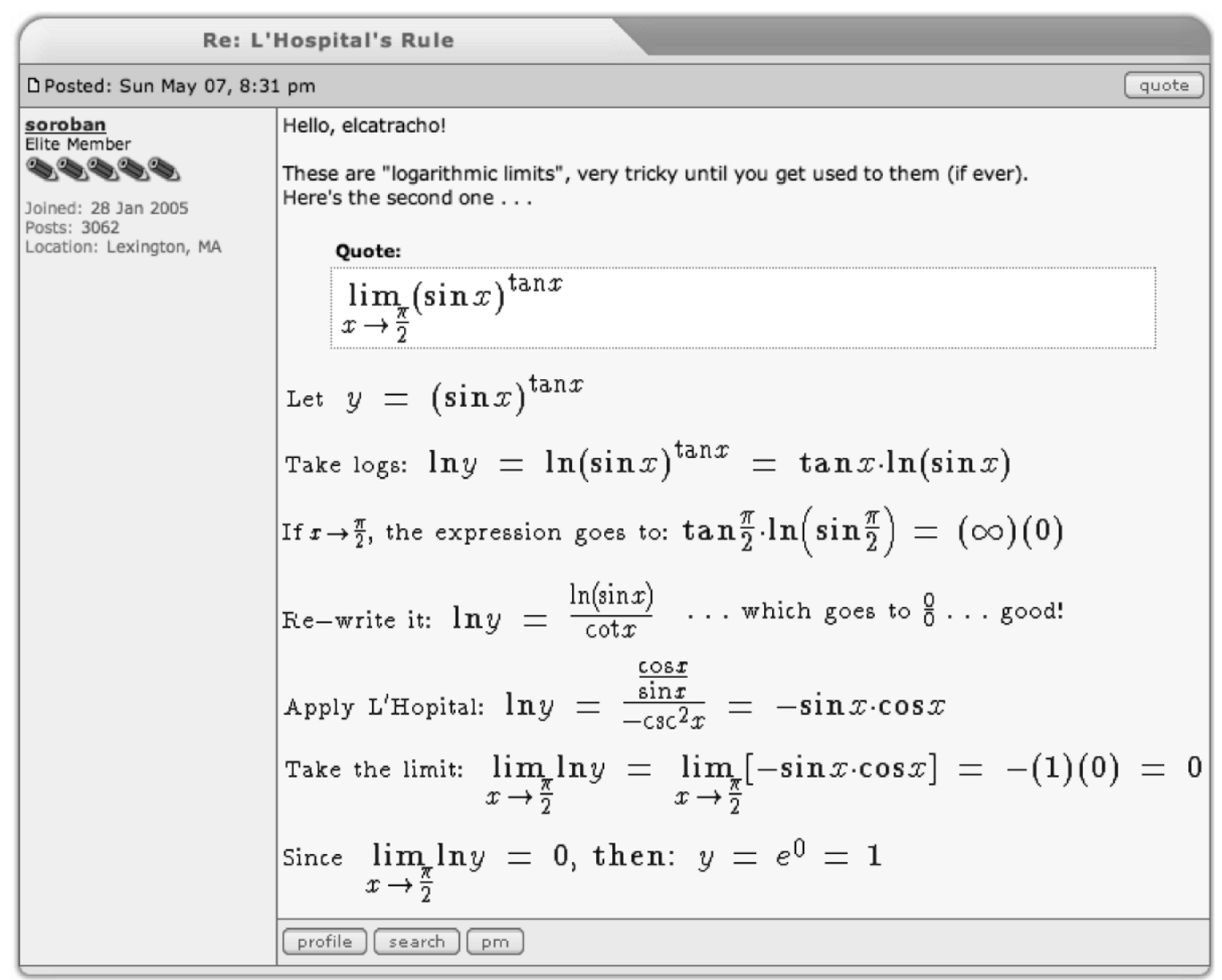

FIGURE 10. An example of load-sharing within an exchange from FreeMathHelp.com.

If the problems in the set are similar to one another (same solution method), then a collaborative effort to respond to all of the problems may constitute too much help; that is, it may discourage the student from using the solution to one as a model (worked example) for attempting the others. In the above exchange, the problems both involve indeterminate forms of exponential form and share a common solution method: taking the logarithm of the expression, writing it as an indeterminate quotient, applying l'Hôpital's Rule, and, finally translating the solution to correspond with the original expression. It is possible that Soroban's contribution may have discouraged the student, Elcatracho, from attempting the second problem on his/her own. However, as Soroban notes, these logarithmic limit problems are "very tricky," it is clear from the student's initial posting that he/she does not understand a critical part of the procedure (expressing the form as an indeterminate quotient), and the solution of the first problem from Pka is sparse with regard to explanatory detail. Thus, in addition to the way tutors collaborate by distributing problems, this example illustrates how tutors attend to the contributions of others and use this information to assess whether the community has met the student's needs.

iv. Load sharing (across exchanges). These online help sites could not exist if tutors did not also work together to share the larger load - the constant stream of queries in need of quick response. All of the sites we investigated had a response percentage greater than $90 \%$, a fact that is especially impressive since the tutors are volunteers. The $\mathrm{AOH}$ site relies on a large number of individuals who each commit to responding to a specified number of queries on a weekly basis. The $\mathrm{SOH}$ sites rely on a large number of individuals who voluntarily frequent the site and 
respond to queries on a regular basis. In both cases, the extensive amount of work required in order to provide a much-needed and valued service is distributed over individuals in a cooperative effort.

v. Distributed expertise. Individual tutors also contribute different types of expertise to the online help sites as a whole. The problems posed, even within a subject area (such as the calculus), range from elementary to advanced, from straightforward to subtle, and from procedural to conceptual. Individual tutors choose to respond to a set of queries based on interest and ability. If a tutor responds to a query but is not entirely satisfied with the result, then he/ she may call on other members for support, as in the previous example from FreeMathHelp.com: "I don't like to use LHopital unless I have to...Perhaps pka, Soroban, Skeeter, or someone will be along with a non-L'Hopital method." In this way, online help sites resemble a collaboration of experts, each contributing his/her subject knowledge.

vi. Problem-solving activity. It is important not to view the online help sites solely as a collaboration of tutors. The students are also a major part of the equation and contribute to the tutoring activity by submitting problems, attempting solutions and querying responses. As many of our examples have illustrated, student contributions reflect how online tutoring encourages students to reflect and engage in mathematical thinking. In an exchange from Cyberpapy. com (Figure 9), the student, Flore/Gimoka, poses a follow-up question to the tutors' advice on one day ("mais papy gérard et la Flégère, je vois bien qu'en posant $\mathrm{y}=1+\mathrm{x}$ on obtient la dérivée $(\ln y-\ln 1) /(y-1)$ pour $\mathrm{y}-->1$ mais comment prouver que --->1") and then (without any intervening exchange) announces that she has figured it out the next ("Bonjour, Je pense avoir compris! La dérivée de $\ln y=1 / \mathrm{y}$ donc $=1$ pour $\mathrm{y}=1$ Merci à tous"). Evidently, the online exchange caused Flore/Gimoka to ruminate on the problem to the extent that eventual understanding was accompanied by excitement and a desire to share this understanding with others. In an investigation of problem solving activity for introductory calculus topics in another $\mathrm{SOH}$ site, $55 \%$ of the exchanges contained either initial or subsequent problem solving activity by the student (van de Sande, 2007).
The defining features of the community can be renegotiated and altered by the members.

All three online help sites provide a means for members to voice suggestions and comments. In MathNerds.com and Cyberpapy.com, members can contact the administrators using e-mail, although there is no indication whether individual or collective efforts have engendered change. FreeMathHelp. com, on the other hand, has a public forum devoted to "administration issues" where members post and respond to the structure, administration, and functioning of the site. On March 6, 2006, a member, SE, posted a suggestion to this forum containing five etiquette principles: Post to an appropriate category, preview or edit your posts for clarity, post the complete text of the exercise, show all of your work, and have patience. These principles were subsequently adopted and are now part of the "Read Before Posting" sticky that heads each forum and outlines the rules for site participation.

FreeMathHelp.com also allows members to author polls so that fellow members have the opportunity to vote on a given suggestion or issue. The administration can then act on these results or not. For example, one member questioned whether we (as a community) should enforce a policy regarding the names of threads and attached a poll for whether or not implementing such measures was a good or bad idea: "Just throwing an idea out here. Maybe we should implement some kind of policy that would require people to name their threads better. I'm tired of seeing "HELLPP!!!" or "calculus" or "Math suxxx!!11 one". I don't know about anyone else, but they aren't very descriptive and remove from the apparent quality of the site itself. Consider something to the effect of first offense a warning to name their thread properly, second and concurrent offenses, continued deletions of topics until they get it." Although only a small number of members responded to the poll, the majority was in favor of some such policy. The site administrator, however, vetoed the result, stating that warnings would not be effective for infrequent visitors, he was against a policy of deleting threads, that tutors might ignore posts with annoying names, and that moderators could edit the names to make them more descriptive. 
Ideas can be questioned, elaborated, challenged, and revised safely.

One of the most valued and sought-after features of a learning community is that all members (learners and instructors) feel free and comfortable to exchange ideas. In particular, mistakes, misunderstandings, and uncertainty need to be resolved in a manner that is constructive and non-threatening. The anonymity of the participants and the public nature of the online exchanges make this venue particularly well suited for this activity. In all three online tutoring sites, there was ample evidence that students do not refrain from publishing mathematical attempts, voicing confusion, and questioning the tutors. In the following example (Figure 11) from MathNerds. com, the student, Richard, posts an initial attempt at solving a limit involving trigonometric functions followed by two responses to the tutor's reply:
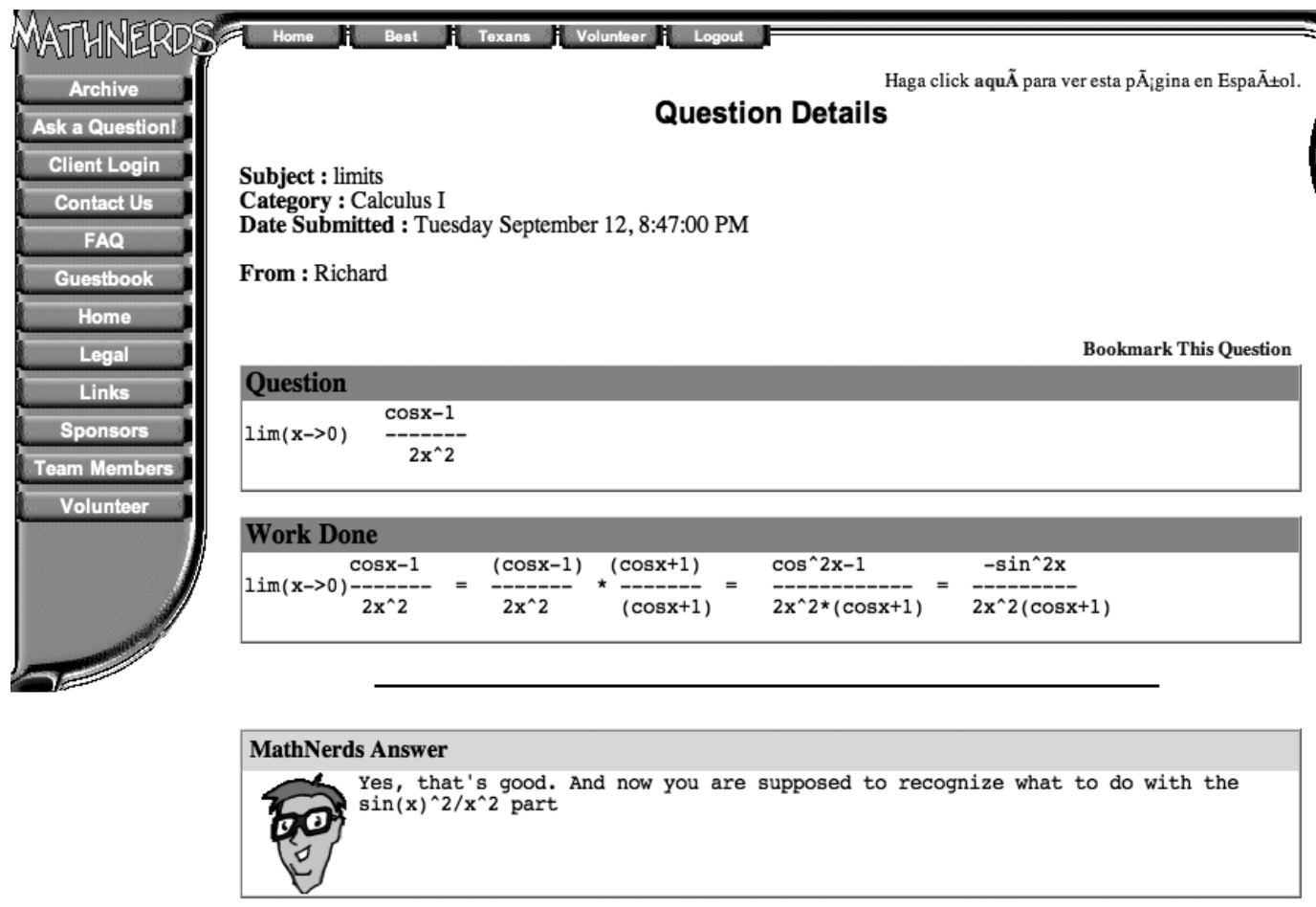

\begin{tabular}{l} 
Richard's Reply \\
can i pull the $x^{\wedge} 2$ out of both and cancel them out \\
Richard's Reply \\
or is $\sin (x)^{\wedge} 2 / x^{\wedge} 2=1$ \\
\hline
\end{tabular}

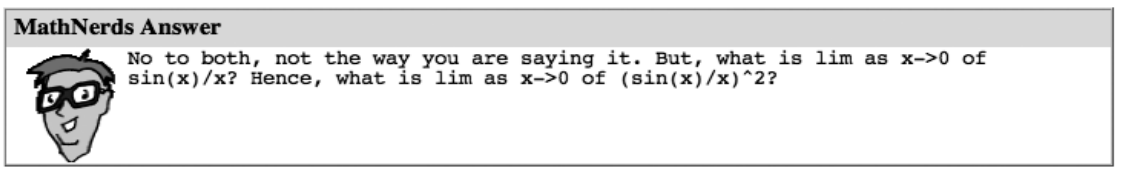

Richard's Reply

ok $i$ see now thank you

FIGURE 11 Exchange from MathNerds.com showing student comfort level. 
Richard publishes two incorrect conclusions following the tutor's advice to focus on a particular part of the expression; One can neither "pull" out nor cancel the $x^{2}$ in $(\sin (x))^{2}$. The tutor gently refutes Richard's conclusions ("No to both, not the way you are saying it.") and provides another hint that focuses attention more specifically on the relevant feature of the expression, namely that $\sin ^{2}(x) / x^{2}=(\sin (x) / x)^{2}$. This moves allows Richard to shift perspective and he responds with gratitude: "ok i see now thank you." In this exchange with its positive outcome, we see Richard presenting an incomplete solution and incorrect mathematical statements that reveal his poor understanding of the (pre-calculus) function concept, and the tutor responding in a constructive manner that is devoid of ridicule.
Tutors, as well as students, should feel comfortable exchanging ideas and addressing mistakes and misunderstandings. Although, ideally, tutors would not make errors, in reality it is not reasonable to assume that this will be the case, especially if the pace is rapid, the framing of the query is ambiguous, or participation is not restricted to experts. We have found evidence that the $\mathrm{SOH}$ sites, in particular, are wikipedia-like ${ }^{15}$. That is, the public nature of these sites generates a self-correcting feature. Mathematical errors are either replaced or addressed and do not generally remain long as the "last word" in a discussion. The following exchange (Figure 12) from FreeMathHelp.com demonstrates the wikipedia nature of the site in an exchange between a student and two tutors involving the limit of a quotient of trigonometric functions of indeterminate form.

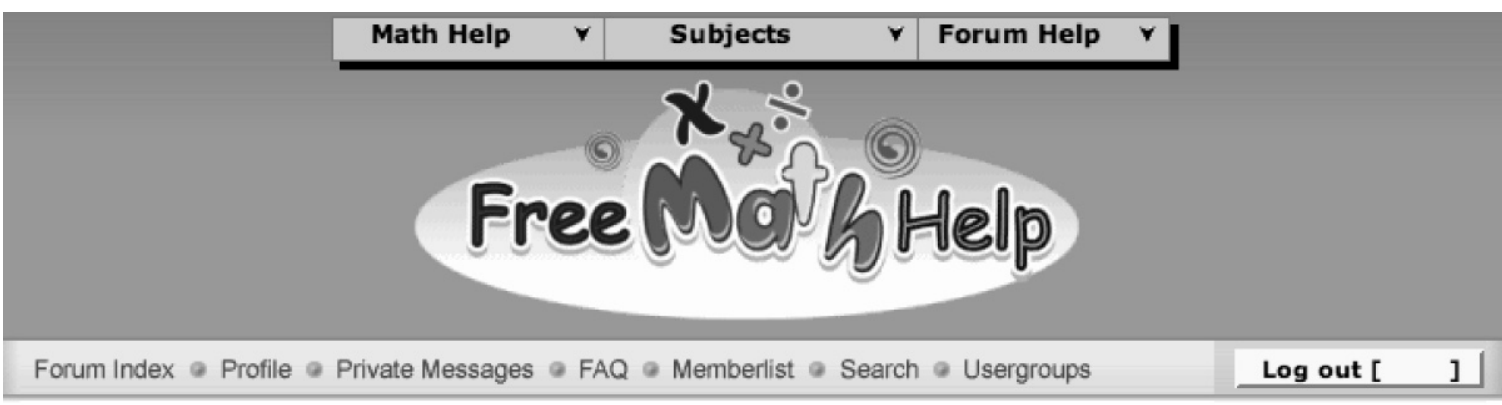

Free Math Help.com - Homework Help! Forum Index " Calculus " Trig limit: lim $[\tan (3 x)] /[3 \tan (2 x)]$ as $x$ goes to zero

\section{new topic post reply}

Solve your tough algebra problems with Algebra Solved!

\section{View posts since last visit View your posts View previous topic :: View next topic}

Trig limit: lim [tan( $3 x)] /[3 \tan (2 x)]$ as $x$ goes to zero

D Posted: Sat Feb 03, 7:49 am

ku1005

New Member

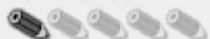

Joined: 27 Oct 2006

Posts: 36
I have been working on the following limit for ages, it seems, and I just don't seem to be getting anywhere -- which ususally means I am missing something obvious. Any pointers would be greatly apprecited!

$\lim x->0$ for $\tan (3 x) / 3 \tan (2 x)$

I first tried the obvious route, substitution, getting a "value" of $0 / 0$, which is no help. Then I converted the tangents into sines over cosines, and tried to work with their respective $x$-values. But I was unable to remove the sine from the denominator, meaning that I would always have something divided by zero. Hints?

Also, do you know of any sites with pointers for solving trig identities, like techniques?

With any luck, I'll have this figured out by the time somebody replies. In either case, thank you for looking at this, and thank you for any help you can offer. 


\begin{tabular}{|c|c|c|}
\hline \multicolumn{2}{|c|}{ Q Posted: Sat Feb 03, 11:20 am } & quote \\
\hline \multirow[t]{2}{*}{$\begin{array}{l}\text { OA } \\
\text { Full Member } \\
\text { Joined: } 20 \text { Feb } 2005 \\
\text { Posts: } 603\end{array}$} & $\begin{array}{l}\tan 3 x / 3 \tan 2 x \lim x-->00 / 0 \text { undefined by L'Hospitals rule take derivatives } \\
1 / 3[\tan 3 x / \tan 2 x] \\
\{1 / 3\}\left\{1 / \cos { }^{\wedge} 23 x / 1 / \cos ^{\wedge} 22 x\right\} \\
\{1 / 3\}\{\cos 2 x / \cos 3 x\}^{\wedge} 2 \lim x-->0 \\
1 / 3 \text { answer } \\
\text { please check for errors } \\
\text { Arthur }\end{array}$ & \\
\hline & profile search $\mathrm{pm}$ email & \\
\hline
\end{tabular}

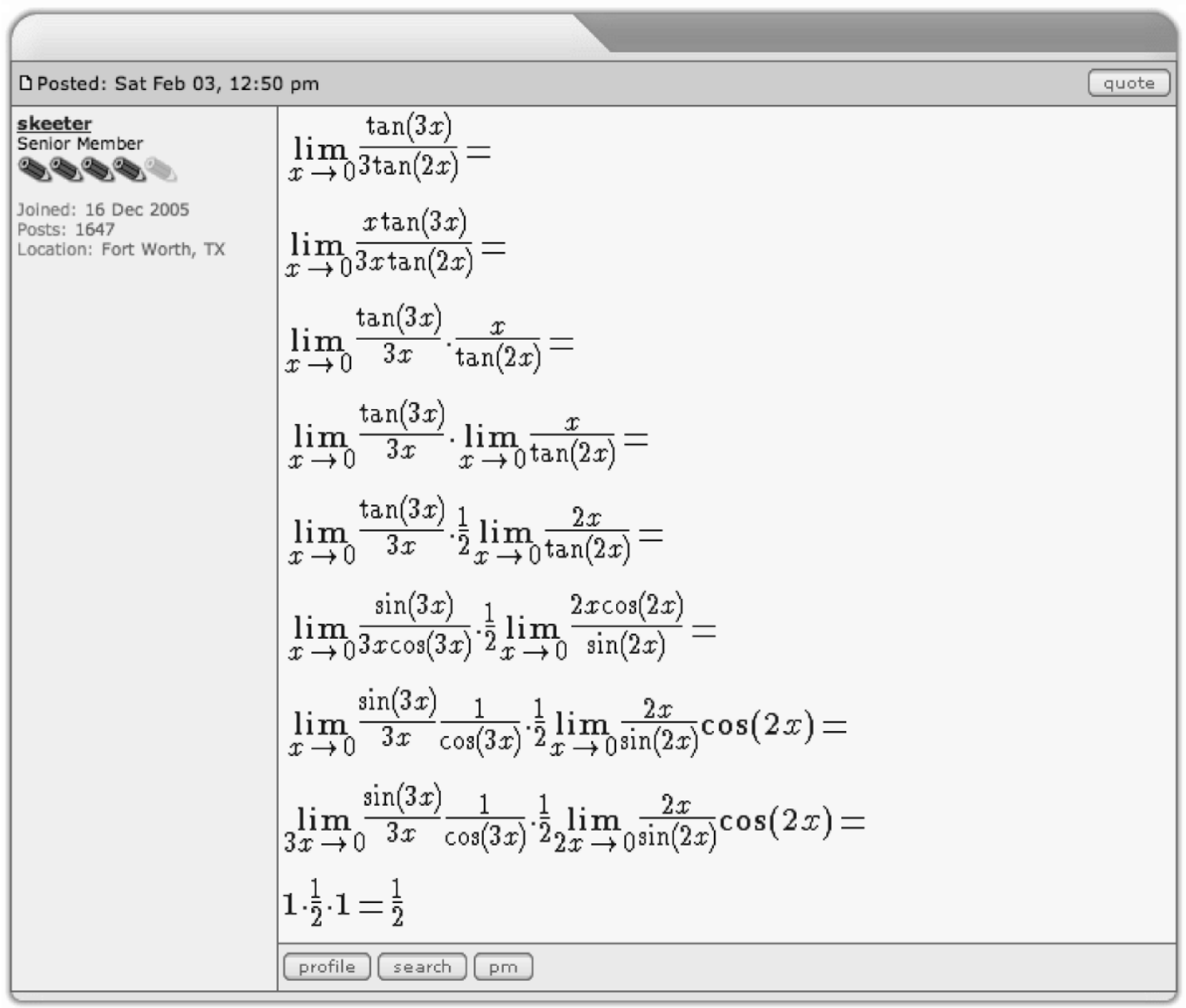


Online Tutoring in the Calculus: Beyond the limit of the limit

Carla van de Sande E Gaea Leinhardt

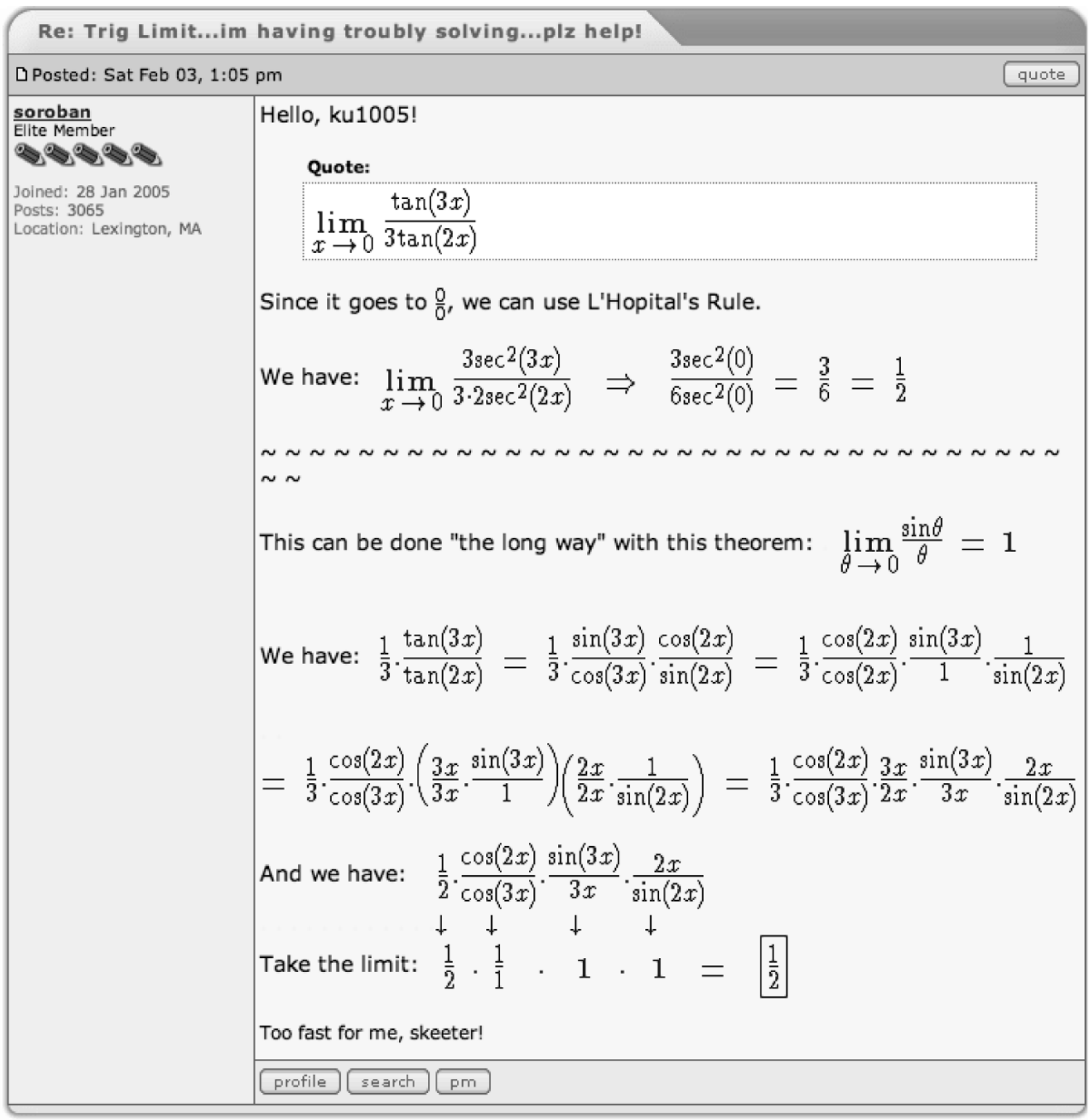

\begin{tabular}{|c|c|}
\hline \multicolumn{2}{|c|}{ D Posted: Sun Feb 04, 12:44 am } \\
\hline \multirow{2}{*}{$\begin{array}{l}\frac{\mathbf{k u} \mathbf{1 0 0 5}}{\text { New Member }} \\
\text { Joined: } 27 \text { Oct } 2006 \\
\text { Posts: } 36\end{array}$} & $\begin{array}{l}\text { thanks heaps for all your help guys...really appreciate it...just dunno how } u \text { do it so fast } \\
\text { lol } \\
\text { but thanks again }\end{array}$ \\
\hline & profile search $\mathrm{pm}$ \\
\hline
\end{tabular}

FIGURE 12 Exchange demonstrating wikipedia-like nature of an SOH site. 
The first tutor to respond, OA, publishes an incorrect solution resulting from mistakes made in the implementation of l'Hôpital's Rule. OA neglects to apply the Chain Rule (necessary for the differentiation of function compositions) when differentiating the functions $\tan (3 x)$ and $\tan (2 x)$ . This results in a final numeral answer that is off by a factor of 3/2. At the end of the posting, OA calls for other members to "please check for errors." The incorrect result is replaced $1 \frac{1}{2} 2$ hours later by a second tutor, Skeeter, using another approach. Instead of applying l'Hôpital's Rule, Skeeter presents a solution based on the "special" limit, $\lim _{x \rightarrow 0} \frac{\sin x}{x}=0$

that U.S. students typically learn prior to l'Hôpital's Rule. The wikipedia-like nature of the site is even more apparent through the actions of a third tutor, Soroban. Soroban replies almost concurrently with Skeeter ("Too fast for me, skeeter!") and posts the correct solution using two approaches: the one that $\mathrm{OA}$ incorrectly implemented and the alternative used by Skeeter. Mathematically, this move demonstrates that it was not the approach that was incorrect (as might be the case) but rather its implementation, and Soroban makes this important distinction explicit: "Since it [the limit expression] goes to $\frac{0}{0}$, we can use L'Hopital's Rule." Thus, the incorrect mathematical information published by OA is effectively erased through replacement with correct information that is promptly supplied by two fellow members of the community.

\section{CONCLUSIONS}

Today's youth belong to the "net generation" (Oblinger \& Oblinger, 2005) and are accustomed to performing activities online that formerly required physical presence. These "digital natives" (Prensky, 2001) routinely use the Internet for a wide range of activities - from shopping, chatting, and playing to working, researching, and studying. Each of these activities is associated with an online venue where participants meet and transactions take place. For receiving help with homework problems, these meeting places have taken the form of free, open online help sites where students can access exper- tise at a click of the mouse. Some of these help sites are staffed by volunteer tutors that have been vetted and are assigned to incoming requests $(\mathrm{AOH})$, whereas others are staffed by volunteers who spontaneously visit and respond ( $\mathrm{SOH}$ ). Also, although the communications are asynchronous, some of the sites operate close to real time (publishing postings as they arrive), whereas other sites institute a delay by either the activity of matching tutor-student pairs or by screening responses.

Just as the structure of a classroom profoundly affects the activity of instruction and learning, so also the structure of an online site impacts the activity of tutoring. $\mathrm{AOH}$ sites promote brief exchanges (one or two turns) between single student-tutor pairs. A tutoring exchange in this context resembles a private consultation with an expert in the domain. A student poses a query and then has access to the ear of an expert, although the privacy normally associated with a consultation is lacking since the exchange is publicly available. SOH sites, on the other hand, encourage extended exchanges between multiple participants. A tutoring exchange in this context often resembles a collaboration of experts that may touch on both mathematical as well as pedagogical issues. A student poses a query and then has access to a community of experts, who jointly converse with the student and may also engage in discussions with one another.

In addition to transforming when tutoring is accomplished and what participation in this activity looks like, online help sites have also transformed who is involved and how those involved work together. Participants of online help sites are members of a community in the sense that they share common goals, meet at a specified location, identify with fellow members, assume responsibility for participation, negotiate features and practices, and are comfortable exchanging ideas. Although a given site does not need to possess a complete set of these features to qualify as a community, the presence of several of these strengthens the sense of a variety of individuals engaged in a collective effort. $\mathrm{SOH}$ sites, in particular, seem to exhibit a strong sense of a community. Members often refer to one another by name, collaborate mathematically, and critique or correct one another to address errors and mistakes. The result is that students, as part of the community, receive more than just mathematical help on 
the problem at hand (for instance, by witnessing mathematical discussions). Tutors, in turn, profit by being positioned jointly as learners (for instance, when other tutors introduce alternative approaches and ways of looking at a problem).

We hope that the research community can profit from this research that represents an alternative approach to the study of tutoring. In contrast to previous research efforts, we have applied an observational methodology to authentic occurrences of student-initiated online help-seeking. We have devel- oped and applied measures for the complexity and quality of the exchanges and explored several ways that these online help sites resemble communities. This is only the beginning of the work needed to gain an understanding of this new and evolving form of tutoring, the impact that it has on students and tutors, and its potential for instruction and learning. Some of the exchanges on the calculus that we have observed show clearly how open online help sites are capable of taking students and tutors beyond the limit of the limit.

\section{ACKNOWLEDGMENTS}

Support for this paper was provided in part by grants from the William and Flora Hewlett Foundation and the Spencer Foundation. The opinions expressed do not necessarily reflect the position or the policy of these foundations and no official endorsement should be inferred. We thank Gérard Sensevy and Ghislaine Gueudet for providing us with details on the calculus curriculum in France; Brett, Joel, and Jessica van de Sande for their organizational and technical help; and members of the ongoing Interaction Analysis seminar chaired by James G. Greeno for discussion of early forms of these ideas. 


\section{NOTES}

1. Generally, these two roles are independent although we have seen some cases in which a student took on the role of a tutor and vice-versa.

2. Although neither author is fluent in French, both have sufficient familiarity to read and work through the mathematical online postings.

3. We were unable to ascertain the nature of the screening criteria from the site administrators.

4. For example, the LaTeX code to produce this limit expression is: $\backslash$ lim_ $\{x \backslash$ to -1$\} \backslash$ frac $\left\{\mathrm{x}^{\wedge} 2-1\right\}\{\mathrm{x}+1\}$.

5. Although the primary purpose is to encourage academic contact between seniors and youth, Cyberpapy.com is a true $\mathrm{SOH}$ site in the sense that anyone (not just seniors) can respond to postings.

6. We sincerely hope that the education research community will respect this decision and not perform experimental studies in online help sites where others are performing observational research.

7. In order to focus solely on the limit concept, we did not include exchanges in which the computation of the limit was part of a larger problem, such as analyzing a function. However, these exchanges are good indicators of what problems and misunderstandings on the limit continue to crop up as students progress through an introductory calculus course.

8. This site does not publish this information, so we based this estimate on the response rate over the time period of our study.

9. This is with the exception of two or three unusually knowledgeable high school students.

10. The published average response time is 22 hours. However, this information is not available in the archives and is thus unknown for the corpus used in this study.

11. A complexity score of 10 is very difficult to realize with only two participants since it requires 7 total contributions (assuming participants alternate turns). The complexity score would have been higher had other tutors participated, but the exchange involved a line of reasoning that the tutor was pursuing with the student and was therefore well-suited to just two participants.

12. We did not include sites where the "support" is offensive or intrusive.

13. In English, it is difficult to type accents and they are often neglected. We quote contributions as they appear in the exchange.

14. This is an example of a student participating in an online site using more than one handle.

15. This feature was first noted and identified by Gaea Leinhardt. Wikipedia (http://en.wikipedia. org) is a multilingual, web-based, free content encyclopedia project in which entries are written and edited collaboratively by volunteer participants from across the world.

\section{REFERENCES}

Bloom, B. S. (1984). The 2 sigma problem: The search for methods of group instruction as effective as one-toone tutoring. Educational Researcher, 13, 4-16.

Brown, A. L. (1997). Transforming schools into communities of thinking and learning about serious matters. American Psychologist, 52(4), 399-413. 
Brown, P. \& Levinson, S. C. (1987). Politeness: Some universals in language usage. Cambridge: Cambridge University Press.

Bruner, J. (1986). Actual minds, possible worlds. Cambridge: Harvard University Press.

Carter, S. L. (1998). Civility: manners, morals, and the etiquette of democracy. New York: Basic Books.

Dunham, W. (2005). The calculus gallery: Masterpieces from Newton to Lebesgue. Princeton, New Jersey: Princeton University Press.

Graesser, A. C., \& Person, N. K. (1994). Question asking during tutoring. American Educational Research Journal, 31(1), 104-137.

Graesser, A. C., Person, N. K., \& Magliano, J. P. (1995). Collaborative dialogue patterns in naturalistic one-toone tutoring. Applied Cognitive Psychology, 9, 495-522.

Grice, H.P. (1989). Studies in the way of words. Cambridge, MA: Harvard University Press.

Grossman, P., Wineburg, S. \& Woolworth, S. (2001). Toward a theory of teacher community. Teachers College Record, 103, 942-1012.

Lave, J. (1991). Situating learning in communities of practice. In L. B. Resnick, J. M. Levine, and S. D. Teasley (Eds.), Socially shared cognition, (pp. 63-82). Washington, D. C.: American Psychological Association.

Leinhardt, G., \& Schwarz, B. B. (1997). Seeing the problem: An explanation from Pólya. Cognition and Instruction, $15,395-434$.

Lepper, M. R., Aspinwall, L. G., Mumme, D. L. \& Chabay, R. W. (1990). Self-perception and social-perception processes in tutoring: Subtle social control strategies of expert tutor. In J. M. Olson \& M. P. Zanna (Eds.), The Ontario Symposium on Self-Inference Processes: Vol. 6. (pp. 217-237). Hillsdale, NJ: Erlbaum.

McArthur, D., Stasz, C., \& Zmuidzinas, M. (1990). Tutoring techniques in algebra. Cognition and Instruction, $7(3), 197-244$.

Oblinger, D. G. and Oblinger, J. L. (2005) "Educating the Net Generation", [online], EDUCAUSE, http://www. educause.edu/educatingthenetgen.

Palloff, R. M. \& Pratt, K. (1999). Building learning communities in cyberspace: Effective strategies for the online classroom. San Francisco: Jossey-Bass.

Person, N. K., Kreuz, R. J., Zwaan, R. A., \& Graesser, A. C. (1995). Pragmatics and pedagogy: Conversational rules and politeness strategies may inhibit effective tutoring. Cognition and Instruction, 13(2), 161-188.

Pólya, G. (1945). How to solve it. Princeton, New Jersey: Princeton University Press.

Pratt, K. (1996). The electronic personality. Unpublished doctoral dissertation, Fielding Institute.

Prensky, M. (2001) "Digital Natives, Digital Immigrants", On the Horizon, Vol. 9, No. 5, ppl-6.

Rissland, E. L. (1989). Example-based reasoning. In J. F. Voss, D. N. Perkins \& J. W. Segal (Eds.), Informal reasoning in education (pp. 187-208). Hillsdale, N. J.: Lawrence Erlbaum.

Siler, S. A., \& VanLehn, K. (2005). The effect of shared experience on one-on-one tutoring. Unpublished manuscript.

Szydlik, J. E. (2000). Mathematical beliefs and conceptual understanding of the limit of a function. Journal of Research in Mathematics Education, 31, 258-276.

Tall, D. (1992). The Transition to Advanced Mathematical Thinking: Functions, Limits, Infinity, and Proof. In D. A. Grouws (Ed.), Handbook of research on mathematics teaching and learning (pp. 495- 511). New York, NY: Macmillan. 
van de Sande, C. (2007). Help! Online calculus tutoring. In D. Remenyi (Ed.), Proceedings of the $2^{\text {nd }}$ International Conference on e-Learning (pp. 497-506). Reading, UK: Academic Conferences Limited.

Werry, C. \& Mowbray, M. (2001). Online communities: Commerce, community action, and the virtual university. Upper Saddle River, NJ: Prentice Hall.

Wertheimer, J. (1998). Among school teachers: Community, autonomy, and ideology in teachers' work. New York: Teachers College Press. 